NBSIR 84-2819

\title{
Estimating Effectiveness of State-of-the-Art Detectors and Automatic Sprinklers on Life Safety in Residential Occupancies
}

U.S. DEPARTMENT OF COMMERCE

National Bureau of Standards

National Engineering Laboratory

Center for Fire Research

Washington, DC 20234 
NBSIR 84-2819

ESTIMATING EFFECTIVENESS OF

STATE-OF-THE-ART DETECTORS AND

AUTOMATIC SPRINKLERS ON LIFE

SAFETY IN RESIDENTIAL OCCUPANCIES

Edward K. Budnick

U.S. DEPARTMENT OF COMMERCE

National Bureau of Standards

National Engineering Laboratory

Center for Fire Research

Washington, DC 20234

January 1984

U.S. DEPARTMENT OF COMMERCE, Malcolm Baldrige, Secretary NATIONAL BUREAU OF STANDARDS. Emeot Ambler, Director 
Page

LIST OF FIGURES $\ldots \ldots \ldots \ldots \ldots \ldots \ldots \ldots \ldots \ldots \ldots \ldots \ldots \ldots \ldots \ldots \ldots \ldots \ldots \ldots$

LIST OF TABLES $\ldots \ldots \ldots \ldots \ldots \ldots \ldots \ldots \ldots \ldots \ldots \ldots \ldots \ldots \ldots \ldots \ldots \ldots \ldots$ vii

Abstract $\ldots \ldots \ldots \ldots \ldots \ldots \ldots \ldots \ldots \ldots \ldots \ldots \ldots \ldots \ldots \ldots \ldots \ldots \ldots \ldots \ldots \ldots \ldots \ldots$

1. INTRODUCTION.................................... 2

1.1 Residential Fire Deaths in the United States............ 2

1.2 Scope and Objectives............................. 3

2. A REVIEW OF DETECTOR AND SPRINKLER TECHNOLOGY............. 3

2.1 The Role of Detectors and Sprinklers as Design

Options for Fire Safety.......................... 4

2.2 Development of Detection Technology................. 4

2.2.1 Limitations in Applying Commercial Detector

Technology to Residential Occupancies............ 6

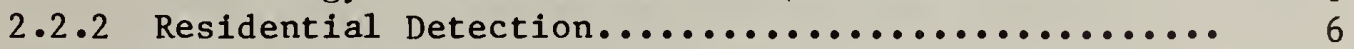

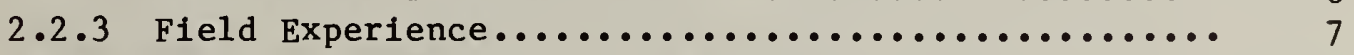

2.3 Development of Automatic Sprinkler Technology ........... 7

2.3.1 Limitations in Applying Standard Sprinkler

Technology to Residential Occupancies............ 8

2.3 .2 Residential Sprinklers....................... 8

2.3 .3 Field Experience........................... 9

3. MAJOR FACTORS IN ESTIMATING POTENTIAL EFFECTIVENESS FOR

RESIDENTIAL LIFE SAFETY........................... 10

3.1 Dominant Residential Fire Scenarios.................. 12

3.2 Location and Capability of Occupants............... 13

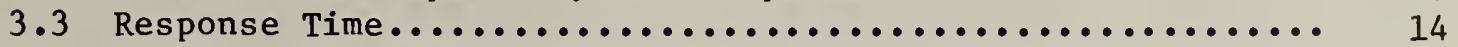

3.4 Impact on Development of Hazardous Conditions............ 15

4. REVIEW OF SELECTED FULL SCALE STUDIES ................... 16

4.1 Mobile Home Studies............................ 16

4.2 Dwelling Studies............................... 19

4.3 Health Care Room-Corridor Studies................... 21

4.4 Implications of Experimental Results for Residential

Life Safety.................................. 23

5. QUALITATIVE ASSESSMENT OF DETECTOR AND SPRINKLER

EFFECTIVENESS .................................... 28

5.1 Assessments................................... 28

5.2 Limitations of the Assessments.................... 30

6. TOWARD APPLICATION OF QUANTITATIVE TECHNIQUES............. 31 
TABLE OF CONTENTS (continued)

Page

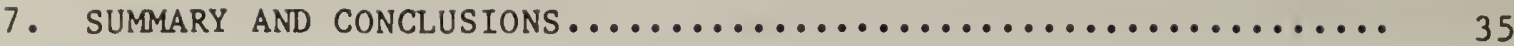

8. ACKNOWLEDGMENTS ................................. 37

9. REFERENCES ..................................... 37 
Figure 1. Occupancy Distribution of 1981 Fire Losses.......... 43

Figure 2. Causes of 1981 Residential Fires................... 44

Figure 3. Growth of Smoke Detector Usage in Single Family

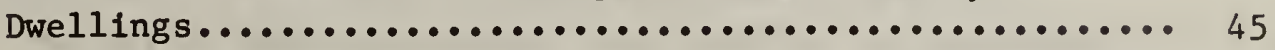

Figure 4. Typical Standard Sprinkler Head and Residential

Sprinkler Head Demonstrating Significant Reduction

in Thermal Link Mass for Residential Sprinkler

Technology................................ 46

Figure 5. Eye Level Temperature and Smoke Density in Room of Fire Origin where Residential Sprinkler Controlled the

Fire.......................................

Figure 6. Illustration of Characteristic Residential Compartment Fires.................................... 47

Figure 7. Parametric Model - Residential Life Safety Scenarios.... 48

Figure 8. Comparison of Activation Times for Smoke Detector (A) and Sprinkler (B) for Typical Compartment Fire.........

Figure 9. Graphical Illustration of Escape Time $(\Delta \mathrm{T})$ provided by

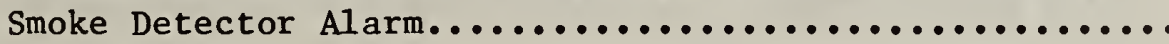

Figure 10. Graphical Illustration of Potential Impact of Sprinklers in Preventing Hazardous Conditions......... 50

Figure 11. Ceiling Gas Temperature and Activation Times: Test 10... 51

Figure 12. Ceiling Gas Temperature and Activation Times: Test 11... 52

Figure 13. Measured Conditions for Flaming Upholstered Chair..... 53

Figure 14. Measured Conditions for Smoldering Upholstered Chair.... 54

Figure 15. Escape Time for Smoke Detectors Installed on Every

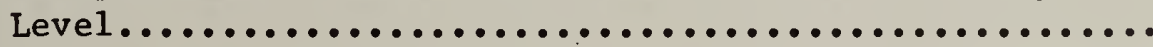

Figure 16. Escape Time for Fixed Temperature Heat Detectors

Installed in Room of Origin................... 56

Figure 17. Ceiling Gas Temperatures in Bedroom Adjacent to Closet for Sprinklered and Unsprinklered Flaming Closet Fires.. 57

Figure 18. Upper Room Gas Temperatures and Sprinkler Activation Times for Smoldering Bedroom Fires................ 58 
Figure 19. Estimated Escape Time from Patient Room and Along Corridor Provided by Different Detector Types

and Locations for Flaming Mattress Fires............. 59

Figure 20. Comparison of Celling Gas Temperatures and Sprinkler

Activation Times for Flaming Mattress Tests........... 60

F1gure 21. Effect of Different Sprinkler Activation Times on

Smoke Filling in Doorway and in Corridor............ 61

F1gure 22. Illustration of Similar Times to Activation for

Residential and Standard Sprinklers under Severe Early

Fire Growth from Shlelded Combustible Wardrobe Fires.... 62

F1gure 23. Parameter Combinations for Scenario Group $\# 1 \ldots \ldots \ldots \ldots$

F1gure 24. Resident1al Life Safety Mode1................... 64

Figure 25. L1fe Safety Objective for Resident1al Occupancies:

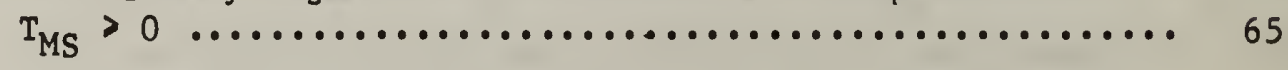

F1gure 26. Relationship of Terms in Expression Proposed for Life Safety $\left(T_{M S}=\left(T_{H}-T_{D}\right)-T_{E, R}>0\right)$ to Resident1al L1fe Safety Model................ 


\section{LIST OF TABLES}

Page

Table 1. Deaths Per Fire: One and Two Family Dwellings......... 67

Table 2. Peak Levels of Selected Hazard Measurements at Eye

Level Elevation.............................. 68

Table 3. Peak Levels of Selected Hazard Measurements at Eye

Level Elevation.............................. 69

Table 4a. Occupant Conditions where Detectors or Sprinklers

Provide Protection - Smoldering/Flaming Scenarios...... 70

Table 4b. Occupant Conditions where Detectors or Sprinklers

Provide Protection - Flaming Scenarios............. 71

Table 4c. Occupant Conditions where Detectors or Sprinklers

Provide Protection - Shielded Fast Flaming Scenarios.... 72

Table 5. Estimated Protection Provided by Detectors and

Sprinklers for Major Interior Fire Scenario Groups in

Residential occupancies...................... 73 



\section{ESTIMATING EFFECTIVENESS OF STATE-OF-THE-ART DETECTORS AND AUTOMATIC SPRINKLERS ON LIFE}

SAFETY IN RESIDENTIAL OCCUPANCIES

\section{Edward K. Budnick}

\section{Abstract}

The report provides a qualitative assessment of the life safety impact of early warning fire detection and automatic sprinkler technology in residential occupancies. This assessment is based on the results of full scale studies and statistics on residential fire fatalities from the NFIRS data base.

Estimates of the impact of three alternatives, smoke detectors, standard automatic sprinklers, and residential sprinklers, are provided for major fire hazard scenarios in residential occupancies. The results of this study indicate that significant life safety benefits can be derived from broad application of detectors and sprinklers in all residential buildings. Further work is necessary to reduce the gaps which exist in our understanding of the performance limits, cost-effectiveness, and reliability of these devices. In addition, there are residential scenarios, for example, occupants intimately exposed to a fire, where the impact of these devices appears marginal.

A quantitative approach is outlined that can lead to a more accurate assessment of the impact of detectors and sprinklers. An initial framework is presented which identifies the key parameters for residential life safety. A mathematical expression is proposed as a success criterion. Work is underway to extend the framework. 
Key Words: F1re losses; life safety; resident1al bulldings; residential sprinklers, smoke detectors; standard sprinklers.

\section{INTRODUCTION}

\subsection{Residential Fire Deaths in the United States}

It 18 well recognized that most fire deaths in the U.S. occur in residential fires. While some varlations occur in the statistics from year to year, "fire deaths in residences" has remalned the dominant category for many years.

In 1973, the report of the National Commission on Fire Prevention and Control estimated that 90 percent of the fire deaths occurred in residential occupancies [1] ${ }^{1}$. While the notion that residential fire losses represented a significant portion of the annual fire $1088 e s$ in the U.S. was not novel, the estimate of the magnitude reported by the Commission drew considerable concern.

Subsequently, the National Fire Incldent Reporting System (NFIRS) was created at the U.S. Fire Administration (USFA) to provide accurate, more detailed reporting of the annual fire losses in the U.S. The most current data from this reporting system (1981) does not vary appreclably from the 1973 estimate from the Commission. The NFIRS data indicates continued overwhelming dominance of residential fires as a source of fire deaths in the U.S. As can be seen in figure 1, while residential fires account for only 25 percent of the annual fires, they account for 80 percent of the deaths and 65 percent of the injuries [2].

of the variety of causes of residential fires, four account for the bulk of fires resulting in deaths and injuries (figure 2). They are smoking, heating, cooking and incendiary/suspicious.

$\overline{1_{\text {Numbers }} \text { in brackets }}$ indicate literature references at end of this paper. 
Finally, the 1981 NFIRS data indicate that the most frequent fatal fire scenarios in residential occupancies involve a single death. While multiple life loss fires are a major concern for some residential occupancies (1.e., apartments, hotels and motels, dormitories), in a sample of one and two family residential fires most deaths ( 94 percent) occurred one or two at a time (see table 1).

\subsection{Scope and objectives}

During the last decade the fire community has directed much of its attention to the matter of life safety, and how advances in technology might reduce the annual fire deaths and Injuries in the United States. The National Bureau of Standards' (NBS) Center for Fire Research (CFR) has conducted research in support of this objective, including studies to contribute to the advancement of early warning fire detection and automatic sprinkler technology relative to life safety. Of particular interest to NBS is the application of such technology in residential occupancies ${ }^{2}$.

This report focuses on the life safety aspects of state-of-the-art early warning fire detection and automatic sprinkler technology. A review of significant technical advancements is provided and an assessment of the potential impact of these advancements on residential fire deaths is presented. This assessment is based on the results of experimental research and information obtained on residential fire deaths from a national data base. Cost/benefit considerations and evaluation of other strategies for life safety are beyond the scope of this study, but are active areas of investigation at NBS.

\section{A REVIEW OF DETECTOR AND SPRINKLER TECHNOLOGY}

While detectors and automatic sprinklers were initially developed to improve property protection in industrial and commercial buildings, they have subsequently been included in nearly all types of buildings. Major fires such as the Coconut Grove Night Club fire (1942) and the Our Lady of Angels Grade

\footnotetext{
2 The term residential occupancy is intended to be consistent with the NFPA 901 Uniform Coding for Fire Protection [3], and includes: one and two family dwellings, apartments, mobile homes, boarding houses, hotels and motels, and dormitories.
} 
School fire (1958) prompted recognition in the fire community of the need for more effective fire protection strategles for prevention of multiple life loss fires. An eventual outgrowth of this has been wider use of detection and automatic sprinklers. Automatic sprinklers have been used to confine the fire to the room of origin; detectors are installed to provide adequate warning to persons outside the room to ensure escape or rescue.

\subsection{The Role of Detectors and Sprinklers as} Design Options for Fire Safety

The principal role of automatic fire detectors is to provide early warning of a fire, allowing sufficient time for occupants to escape or take some defensive action before they are overcome by hazardous conditions. While detectors can also serve to initiate other fire safety devices such as door closers, suppression systems, and smoke control systems, they can not protect occupants or control a spreading fire. For life safety, automatic detection requires that occupants are mobile, or that prompt assistance be available.

Automatic sprinklers provide a means of controlling a developing fire, providing additional time for escape. In addition, to the extent that hazardous conditions are avoided, occupants could potentially survive the incident without requiring escape. This capability is particularly important when occupants are 1mmobile, and rescue is unlikely.

\subsection{Development of Detection Technology}

Heat detectors, the oldest form of automatic detection, were initially the by-product of thermally activated sprinkler heads (late 1800's). Early advancements in heat detector technology resulted in two basic types: one which responded at a prefixed temperature threshold and one which responded to a rate of temperature rise [4]. Heat detectors are best sulted for fire detection in small confined spaces where rapid heat generation can be expected from a fire, or in areas where environmental conditions are unsuitable for more sensitive detection devices. For many years these two types of heat 
detectors were considered the industry standard for fire detection in industrial and commercial buildings. And except for subtle changes in design, these two types are still used extensively in protective signaling systems.

The most significant development in detector technology in terms of breadth of applicability was the introduction of the smoke detector. Conventional smoke detectors operate by one of two principles, photoelectric or ionization chamber [5]. Photoelectric smoke detectors utilize either light scattering or light absorption techniques to measure smoke accumulation in a sensing chamber. Ionization chamber detectors utilize a small radioactive source material to ionize the air in the sensing chamber, rendering it conductive, resulting in an electrical current flow between two electrodes. Smoke which enters the chamber decreases the conductance of the air until a threshold is reached, resulting in alarm.

The notion that smoke would be appropriate as a detection mechanism was not immediately accepted. The relative high cost, limited availability, and untested performance deterred the development of smoke detector technology until results of a series of field tests conducted by the Los Angeles Fire Department, popularly referred to as Operation School Burning, was published in 1960 [6]. This was the first well-documented evidence that activation of smoke detectors preceded heat detectors in most cases. Publication of these results marked a milestone in the recognition of smoke detector technology, which has grown rapidly in popularity since 1960 .

Heat and smoke detectors have been installed extensively in industrial, manufacturing, commercial and public buildings, as well as some of the larger residential and institutional buildings. Generally they are installed as part of a building-wide alarm system which is also frequently tied into the local fire department. The purposes of such systems are to provide early warning to building occupants, and rapid notification of the fire department to reduce the delay before initiation of fire fighting and rescue operations. 


\subsubsection{Limitations in Applying Commercial Detector Technology to Residential Occupancies}

Commercial heat and smoke detector systems are appropriate for many residential occupancies (e.g., dormitories, hotels and motels). However, commercial heat detector systems are less attractive for single family housing, moblle homes, apartments, and other similar types of residences because they operate too slowly to provide adequate life safety for many residential fires, and are prohibitively expensive. Although commercial smoke detector systems frequently provide significantly earlier detection of fires than heat detector systems, the cost alone has limited their application in residential occupancles.

\subsubsection{Residential Detection}

In response to the need to provide economical, early warning fire detection for residential occupancles, the fire detector industry developed a "single station" smoke detector. By the mid-1960's, such devices were ava11able for installation as individual units, rather than as components of the more expensive "systems". In 1967, the National Fire Protection Association (NFPA) published the first edition of NFPA 74, Standard for Installation, Maintenance and Use of Household Fire Warning Equipment [7], providing information on types of detectors, operating principles, installation guidelines and maintenance practices.

The use of "single station" smoke detectors got off to a slow start in the 1960's. However, through improvements in design, significant cost reductions, aggressive marketing, and mandatory legislation in local jurisdictions, residential smoke detectors became read1ly avallable during the 1970's, providing an economical means of early warning detection for residential occupancies. Figure 3 provides an 1llustration of the growth of smoke detector usage in single family dwellings during the 1970's. It is estimated that by 1982 up to 67 percent of the dwellings in the United States had Installed smoke detectors [8]. 


\subsubsection{Field Experience}

The life safety impact of commercial heat and smoke detector systems is not well documented. The use of such systems in industrial and commercial occupancies to provide warning and rapid fire department response has generally been considered successful. There is anecdotal evidence that such systems have saved lives in hotels, motels and apartment buildings where large numbers of people outside the immediate area of the fire were provided sufficient time to escape. Studies such as that conducted by Hall [9] in 1979 have attributed a number of multiple death fires in apartments, nursing homes and hotels to the absence of any early warning detection systems.

The life safety impact of single station smoke detectors on residential fire deaths is somewhat better documented, and has been very encouraging. Review of the NFIRS data base indicates that the likelihood of death for fires in dwellings without smoke detectors is 2.5 times higher than the rate in dwellings with detectors [10]. Recent studies of mobile home fire fatalities indicate that the death rate is 2-4 times higher in mobile homes without detectors $[11,12]$.

\subsection{Development of Automatic Sprinkler Technology}

Automatic sprinkler systems consist of a network of piping with geometrically spaced nozzles referred to as sprinkler heads. Typically the piping system is connected to a central water supply and the individual sprinkler heads are activated by heating of a thermal link by the hot gases from the fire.

Sprinkler systems, first installed in textile mills in the $1850^{\prime} \mathrm{s}$, were intended to reduce the likelihood that an entire building or complex would be destroyed by fire [13]. By 1930, the NFPA Standard for Sprinkler Installation (NFPA 13) [14] recognized three types of sprinkler systems, based on water requirements to control or extinguish fires of different magnitudes. These designations, the "light hazard system", the "ordinary hazard system", and the "extra hazard system" continue in use today as a basis for design requirements. 
A gradual development in sprinkler technology has followed the initial design used in the textile mills. The sprinkler head as we know 1 today was first introduced in 1878 [15]. Most developments up through the 1960's centered on the water spray patterns, with a major development being the introduction of the "Standard" sprinkler head in the early 1950's by the Factory Mutual System [16]. The standard sprinkler was characterized by redesign of the deflector to discharge the water downward, with a unfform pattern. While other extensions of the technology were introduced, such as the ultra high-speed sprinklers which were activated by an explosive valve (1959), and the on-off sprinkler which is capable of shutting itself off, the basic sprinkler system commonly found in industrial, commercial and public bulldings today has changed very litle since the introduction of the standard sprinkler head [17].

\subsubsection{Limitations in Applying Standard Sprinkler Technology to Residential Occupancies}

As is the case with commerclal detection systems, application of conventional standard sprinkler technology to residential occupancles has been limited, primarily due to the cost of installation and maintenance of such systems designed in accordance with NFPA 13. While NFPA 13 sprinkler systems are found in some hotels, motels, etc., they are not typically required, and 1t is uncommon to find such systems in dwellings, mobile homes, and apartments .

\subsubsection{Residential Sprinklers}

New technology was developed in the 1970 's to overcome this barrier to the application of automatic sprinkler systems to residential occupancies.

The NFPA created a new standard in 1975, the NFPA 13D Standard for Installation of Sprinklers in One and Two Family Dwellings and Mobile Homes [18]. While the initial version of this standard relied principally on existing standard sprinkler technology 1t was recognized that changes in state-ofthe-art sprinkler design would be necessary. Research to provide these 
changes focused on providing life safety protection for fire hazards unique to residences, and on system designs which were more economical than the typical NFPA 13 sprinkler design.

A major source of cost associated with NFPA 13 sprinkler systems is the water supply. Therefore, initial research $[19,20]$ focused on reducing the water supply requirements for residential sprinklers exposed to typical residential fires. The results of this initial research disclosed that for certain fire scenarios typical of fires which occur in residences, standard sprinklers did not provide adequate life safety with a reduced water supply.

An outgrowth of this research was the introduction of the "residential rapid response" sprinkler head [21-23]. While similar in appearance to standard sprinkler heads, the residential sprinkler has a thermal link with a much smaller mass, resulting in quicker activation by a growing fire (figure 4). The more rapid response characteristics of the residential sprinkler resulted in suppression action much earlier in a developing fire. Full scale testing [22] indicated that for many residential fire scenarios, suppression was initiated prior to attainment of conditions hazardous to life safety. In addition, extinguishment of the fire was achieved with less water demand than typically required in an NFPA 13 system design.

This has been recognized as the most significant development in sprinkler technology since the development of the"standard" sprinkler, and demonstrates considerable promise in terms of reduced costs and improved performance for residential applications.

\subsubsection{Field Experience}

While the development of residential sprinkler technology has been too recent to provide in situ experience, standard sprinkler system performance has been well documented. In non-residential occupancies, the average property loss from fires is far less when sprinklers are installed. For example, in a six year study of mercantile buildings by Factory Mutual Research Corporation (FMRC) a property loss-per-fire ratio was found to be $10-$ to-1 between unsprinklered and sprinklered buildings [24] 
Other studies, though limited in terms of the size of the data base and the specialized nature of the occupancles, also provide some evidence of the impact of sprinklers on property losses. A nine year study of U.S. Army supply warehouses reported a property loss-per-fire rat1o of 107-to-1 for unsprinklered and sprinklered warehouses [25]. Studies of Navy and Marine warehouses [26], and U.S. Department of Energy (DOE) fac1l1t1es [27] reveal similar benefits.

Substantial evidence of the reduction in property losses due to sprinkler systems is avallable. In addition, limited information on the impact on $11 \mathrm{fe}$ safety is reported in the 11terature. A prominent New Zealand/Australian survey reported only five deaths over 90 years in 5,734 fire incidents where automatic sprinklers were present [28]. In addition, a DOE study which spanned a period of 28 years (1952-1980) reported no fatalities in sprinklered DOE facilities [27]. These statist1cs, along with NFPA records which indicate that there have been no multiple life loss fires in sprinklered bulldings in the U.S [29], offer evidence that sprinklers have an impact on life safety. However, the magnitude of the impact is difficult to discern when one considers that most fire fatalities occur in residential occupancies one and two at a time (refer to section 1), the above statistics have limited relevance. Less than three percent of the cases in the New Zealand/Australian study and none of the DOE cases involved residential occupancles. In addition, there were no fatalities in any DOE facilitles over the period studied, whether or not sprinklers were installed. Therefore, the information should be treated as anecdotal, but certainly encouraging.

3. MAJOR FACTORS IN ESTIMATING POTENTIAL EFFECTIVENESS FOR RESIDENTIAL LIFE SAFETY

Field experience indicates that the significant benefits that have been derived from the use of conventional detection and standard sprinkler technology in averting multiple life loss have resulted largely from protection of persons outside the room of fire origin. However, most fire deaths in residential occupancies occur in ones and twos, many of them either from immediate exposure to small, slow developing fires, or intimate exposure to clothing or bedding fires. 
Smoke detectors can provide adequate time to escape for many cases. But in those cases where occupants are intimately exposed to the fire, or immobile and therefore unable to escape, a smoke detector may have little or no benefit. As an example, in a study of 342 fatal residential fires conducted by McGuire and Ruscoe [30] in 1962, it was concluded that up to 41 percent of the deaths could have been averted by smoke detectors. The remaining 59 percent of the deaths could not have been prevented by smoke detectors alone because the occupants were immobile, intimate with the fire, or exposed to very rapid fires (e.g., flammable liquids). An ongoing study at NBS [31] indicates similar limitations in smoke detector performance.

The field experience with standard automatic sprinklers demonstrates a high level of success in reducing the number of fatalities in various occupancy types. Field experience also indicates that standard sprinkler systems are less effective for individuals located in the room of fire origin, particularly in residential occupancies where small volume rooms permit rapid development of hazardous conditions. In these cases, the inherent delay in system activation due to the thermal lag of the sprinkler heads' sensing element results in generation of hazardous conditions prior to initiation of suppression action. A 1974 report from the State of Oregon indicated that nine of 13 deaths in Oregon nursing homes had occurred in sprinklered buildings [32] All nine fatalities were single patient fatalities in which the person died in the room of fire origin, before the sprinkler system was activated. A review of 1976-79 NFIRS data by NBS [33] indicates that 35 percent of all single fatality nursing home fires occurred in sprinklered buildings. And, current NBS estimates for dwelling fires indicate that up to 36 percent of the fatalities occur to occupants who are in the room of fire origin and possibly intimately exposed (e.g., clothing ignition) to the ignition [34].

Although, there is little field experience with rapid response residential sprinklers, results of full scale experiments indicate that a significant portion of those residential fatalities that may be unsavable with standard sprinklers due to the inherent delay in sprinkler head activation may be adequately protected by residential sprinkler technology $[22,23,35,36]$. As illustrated in figure 5, results of full scale fire tests show that devices demonstrating the thermal response characteristics of residential sprinklers 
can in most cases activate before hazardous conditions ${ }^{3}$ are reached in the room of fire origin. Although people who are intimate with the fire may remain unsavable, those who are not intimate with the fire but are in the room may survive, whether they are immobile or not. NBS estimates [31] 1ndicate that many one and two family residential fire deaths and infuries could be averted by the quicker responding residential sprinklers alone. And, residential sprinklers in conjunction with smoke detectors could potentially provide an even greater reduction in residential fire fatalities and injuries.

This discussion suggests that both the performance benefits and the limitations of detector and sprinkler devices can have a significant impact on Iife safety expectations. Therefore, any estimate of the impact of detector or sprinkler technology on fire fatalities in residential occupancies requires consideration of key factors which affect the performance. Such factors include:

(1) the major fire hazard scenarios

(2) the location and capabilities of the occupants

(3) the response time of detector or sprinkler

(4) the effect on the development of hazardous conditions

\subsection{Dominant Residential Fire Scenarios}

Gomberg, Buchbinder, and offensend [43] performed a detailed analysis in which residential fires were grouped under nine major scenarios. For purposes of this study the major fire scenarios identified by Gomberg, et al. can be classified by location of ignition, and fire growth characteristics. That 1s,

\footnotetext{
3 While the state-of-the-art does not permit a precise assessment of the direct hazard to humans of exposure to fire conditions, a number of studies provide estimates of levels at which adverse effects occur [37-42]. In this study, estimates of hazardous levels of gas temperature, carbon monoxide, oxygen and smoke density were selected based on review of these studies. These levels, which are considered approximate, are:

Temperature $>100^{\circ} \mathrm{C}$

Carbon Monoxide > $8,000 \mathrm{ppm}$ or $50 \% \mathrm{COHb}$

oxygen < $12 \%$ by volume

Smoke Density $\rangle .25-.50 \mathrm{oD} / \mathrm{m}$
} 
Ignition locations include: (1) outside the dwelling; (2) inside the dwelling, but within a concealed space, and (3) within a room. Fire growth is separated into three groups; smoldering/flaming, flaming, and fast flaming. These three characteristic fires provide sufficient variation in fire development to reasonably represent abroad range in typical residential fires, Including the four major causes of residential fire fatalities, $1 . e .$, smoking (smoldering/flaming), cooking (flaming), heating (flaming) and incendiary/suspicious (fast flaming).

The growth characteristics of these three types of fires are 1llustrated in figure 6. Smoldering/flaming fires, including ignition of furniture by smoking materials, are characterized by a long early growth period where only a slight increase in room temperature and slow emission of combustion products occur. Flaming fires may include furniture ignitions as well as other incidental ignitions, resulting in 1mmedlate flaming. This type of fire is characterized by a shorter early growth perfod, during which combustion products adverse to life safety are usually given off in greater quantities than in smoldering fires. Flaming fires also are accompanied by a higher temperature rise during early growth. Fast flaming fires are characterized by almost no early growth stage. Such fires typically include incendiary/suspicious fires, or those involving flammable liquids, gases, or explosives, and enter the transition stage leading to a fully developed room fire very quickly. In addition, shielded fires such as concealed space or closet/wardrobe fires may also be characterized as fast flaming.

\subsection{Location and Capability of Occupants}

For purposes of this study, three situations were identified which describe the location of an individual with respect to his/her exposure to a developing fire. One situation involves those persons who are intimate with the ignition. Typical examples include clothing ignitions and bedding or upholstered furniture fires where a person is directly exposed to the fire. The second situation includes persons who are in the room where the fire starts, but are not directly exposed. The third sttuation includes persons who are outside the room of fire origin at ignition. 
In addition to location, the capabilities of the individuals in terms of their ability to escape are important. Therefore, consideration was given to whether or not the individual is awake or asleep, and whether or not they are mobile or 1mmobile. For purposes of this study, immobile includes the very young or very old, and the physically or mentally impaired, including 1mpairment from drugs or alcohol.

To systematically examine the possible combinations of factors which represent the dominant cases for fatal fires in residential occupancies, a parametric model was constructed (figure 7). Appropriate combinations of the fire scenario parameters (fire type, fire location) and the occupant location and capability parameters (location, status) can be readily selected for consideration of detector or sprinkler effectiveness. The scenarios examined in this study are representative of most residential fire fatalities.

\subsection{Response TIme}

As discussed in section 2, smoke detectors respond to an accumulation of smoke particulate within the devices' sensing chamber. In a developing fire, the response will depend on a complex interrelationship of environmental factors such as fire size and growth rate, fuel type and smoke generation rate, room geometry and ventilation, and detector characteristics such as location, smoke entry characteristics and predetermined detector sensitivity thresholds. Sprinkler heads, activated by a thermal sensing element, are affected by similar environmental factors such as room size, ventilation rate, and the rate of heat release of the fire, and by location in the room, as well as the temperature and the heat transfer characteristics of the sensing element.

While the rate of temperature rise and smoke production are both functions of the rate of fire growth, quantities of smoke sufficient to activate a smoke detector generally precede a gas temperature sufficient to activate a sprinkler. Therefore, considerable differences in response time can occur between smoke detectors and automatic sprinklers as a result of differences in the sensing medium. A conceptual illustration is provided in figure 8 . 
Extensive research has been conducted to develop quantitative methods to predict the response characteristics of detectors and sprinklers, and their performance in compartment fires [44-47]. Good progress has been made, but in order to permit generalized calculations of detector or sprinkler response for a wide range of environmental conditions, these models must be expanded in scope to provide a more complete account of variations in the physical processes associated with compartment fires. Work is continuing in this area to provide and validate such generalized models.

\subsection{Impact on Development of Hazardous Conditions}

Figure 9 provides a simple graphical illustration of the primary role of smoke detectors, to alert occupants and provide sufficient time for escape. A simple expression has been proposed by Cooper [48] as a means of analytically describing this process:

$$
\mathrm{T}_{\mathrm{E}} \leq \mathrm{T}_{\mathrm{H}}-\mathrm{T}_{\mathrm{D}}
$$

where

$$
\begin{aligned}
& \mathrm{T}_{\mathrm{E}}=\text { time required to escape } \\
& \mathrm{T}_{\mathrm{H}}=\text { time to reach hazardous condition } \\
& \mathrm{T}_{\mathrm{D}}=\text { time to detection }
\end{aligned}
$$

The behavior of a smoke detector can have a substantial effect on escape time, even though it can't directly affect the growth of the fire. For example, a more rapid response, which can be accomplished by increasing detector sensitivity, or decreasing spacing, will increase the time avallable for escape.

A sprinkler system can have a direct impact on the development of the hazard (figure 10). The level of success of a sprinkler system in controlling hazardous conditions depends on when the system is activated, the capacity of the system to suppress or extinguish the fire, and the effects of other design features. Research is active in these areas, but it will be some time before these factors are adequately understood to permit accurate, quantitative prediction of their effects on hazard development for generalized cases. 
In the absence of methods to predict the performance of a particular detector or sprinkler device, large scale experimental studies have been conducted to provide estimates. While such studies are not comprehensive in terms of examining the interrelationships of the key parameters outlined above, the results of these studies provide insights regarding performance. A brief review of selected studies is presented in the following section. The results of these studies provide the basis for estimates used in this study on the impact of detector and sprinkler technology on fire fatalities in residential occupancies.

\section{REVIEW OF SELECTED FULL SCALE STUDIES}

In recent years CFR has supported full scale experimental studies designed to examine the life safety benefits of selected design strategles, including detectors and automatic sprinklers. These studies have provided experimental measurements of detector response times, sprinkler activation times and the impact on the development of hazardous conditions from typical room fires for geometries representative of mobile homes, single family dwellings, and hospital patient rooms. The studies of geometry and environmental conditions in the patient room also provided insights into the expected performance of detectors and sprinklers in other residential occupancies such as hotels, motels and apartments. The results of these studies provide some of the information necessary to estimate the performance of detector and sprinkler devices under conditions representative of actual fires in residential occupancies.

\subsection{Mobile Home Studies}

Full scale studies conducted by Budnick and Klein $[38,49]$ provide quantitative measurements of the development of hazardous conditions in typical mobile home structures from incidental ${ }^{4}$ fires. In these studies hazardous conditions developed almost uniformly throughout those portions of the space

\footnotetext{
${ }^{4}$ An incidental fire is a typical residential fire which intially involves a single item or small fuel package, but if unimpeded, will spread throughout the room, and beyond to adjacent spaces [50].
} 
open to the room of fire origin. Therefore, in considering life safety, the available time before hazardous conditions were reached was nearly the same throughout the structure, unless the occupant was behind a closed door.

The development of hazardous conditions is dependent on the rate of fire growth, and the impact of a particular detector or sprinkler on life safety will be substantially affected by that rate. In figures 11 and 12 , ceiling temperature in the room of origin is plotted continuously for two tests conducted by Budnick and Klein. The times at which thresholds for hazardous conditions were reached, based on the criteria presented in section 3 , are indicated on the plots, along with the response times for smoke detectors used in the experiments. In addition, estimates of activation times for a $135^{\circ} \mathrm{F}$ fixed temperature heat detector, a residential rapid response sprinkler ( RTI $\sim 41)^{5}$ and a standard sprinkler $($ RTI $\sim 100)$ are provided 6 .

Test 10 (figure 11) is characterized by a short incipient fire growth period, followed by transition to rapid flaming. The short incipient growth period provided a limited amount of time for escape or defensive action, and the inherent delay in thermally activated devices such as heat detectors or standard automatic sprinklers would provide marginal life safety benefits. However, even for this type of fire where hazardous conditions were reached quickly, the residential smoke detector responded in sufficient time to provide more than three minutes of escape time. It was also estimated that the residential sprinkler would have activated before transition to rapid fire growth, preventing the development of hazardous conditons.

5 The response time index (RTI) for thermally activated links:

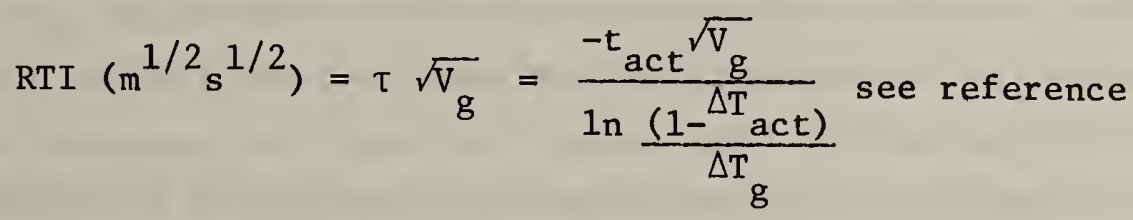

6 The RTI values of 41 and 100 were selected as typical for residential and standard sprinklers. It should be recognized that significant variations occur in RTI values among the many sprinkler heads commercially available. 
In test 11 (figure 12), the incipient fire growth period was much longer, characteristic of a smoldering or slowly developing flaming fire. While a smoke detector provided an extended period for escape time $\left(T_{H}-T_{D}>8\right.$ minutes), the very low temperature levels would have delayed the operation of a heat detector or a residential sprinkler considerably, resulting in a limited impact on life safety. The greater thermal lag for a standard sprinkler (RTI 100 to 300 ) would have delayed activation until transition to rapid fire growth occurred, and hazardous smoke levels were exceeded.

In these two tests smoke detectors provided the earliest warning, and therefore the maximum time to escape, provided that the occupant is mobile, and not intimate with the fire. Residential sprinklers and heat detectors activated in the room of fire origin at about the same time, and before the onset of hazardous conditions. However, the delay associated with the thermal $1 \mathrm{ag}$ of the heat detector reduced the escape time significantly. The low temperature levels resulting from a slowly developing fire may delay the response of a residential sprinkler, allowing hazardous levels of smoke and toxic gases to be approached or exceeded before suppression is initiated.

The inherent thermal $1 \mathrm{ag}$ of a standard sprinkler would have resulted in delayed activation until transition to rapid fire growth occurred, and hazardous conditions were approached. Therefore, the life safety benefit to occupants in the room of origin, and in communicating spaces open directly to the room would be marginal.

Bukowski [52] also conducted full scale tests in a mobile home to study environmental effects on smoke detector response. His results for flaming upholstered chair fires are consistent with results reported by Budnick and Klein. Figure 13 illustrates the early response of the smoke detectors, and the subsequent response of the thermally activated devices. As in the earlier study, the $135^{\circ} \mathrm{F}$ fixed temperature heat detector and the residential sprinkler would have activated before hazardous conditions were reached, but the heat detector would provide considerably less escape time than that provided by the smoke detectors. The test fire was manually extinguished before a standard sprinkler would have activated. 
Bukowksi also conducted smoldering upholstered furniture fires. Figure 14 illustrates the results of a typlcal smoldering test, characterized by an extended incipient burn period, followed by rapid transition to flaming. While smoke detectors activated during the incipient period - providing extended escape time, the thermally activated heat detectors and sprinklers would not have activated unt1l rapid flaming occurred. Although a residential sprinkler would most 11kely have extingulshed the fire, hazardous levels of smoke were reached long before 1t would have activated. The rapld deterioration in conditions following transition to flaming would have seriously threatened the 11ves of immobile or unaware occupants close to the fire. A standard sprinkler would have activated soon after the residential sprinkler, but the very rapid fire growth following transition to flaming would most likely result in untenable conditions by then.

\subsection{Dwelling Studies}

CFR funded a major series of full scale tests [53] in the mid-1970's to provide field data and performance criteria for the installation of detectors. The results of this experimental work served as the basis for current installation requirements for residential detectors in NFPA 74 . The results of these tests provide insight into issues of life safety in residences and the effects of heat and smoke detectors.

The tests were conducted in a one story and in a two story dwelling. Gas temperatures, carbon monoxide, oxygen depletion, and smoke density were monitored throughout the dwellings, particularly along the escape paths, for a variety of flaming and smoldering fires. The adequacy of detectors positioned at different locations in providing minimum required escape time (estimated by the investigators at 2 minutes) was assessed. The results indicated that a smoke detector must be located on the story (e.g., floor) where the fire starts in order to provide adequate escape time. It was found that heat detectors in the room of fire origin provided little or no escape time.

Figure 15 illustrates the success frequency, defined as the frequency where a minimum of two minutes of escape time was achieved, when a smoke detector was located on each floor of the dwelling. In every case the smoke 
detector alarmed before hazardous conditions were reached in the room of fire origin, along the escape path, or in remote rooms. In greater than 90 percent of the cases, the escape time provided was greater than two minutes, the minimum value set for this study. Assuming that occupants are mobile, not intimately exposed to the fire, and an escape time of two minutes is sufficient, smoke detectors installed on every level of the dwelling provided adequate protection for escape for all the test fires conducted in this series.

The success frequency for heat detectors located in the room of origin is shown in figure 16. These results indicate that a minimum escape time of two minutes was provided in 60 percent of the flaming tests, and 25 percent of the smoldering tests. For a number of tests, hazardous conditions were exceeded before the heat detector responded, rendering marginal or no life safety benefit to the occupants.

CFR and USFA jointly sponsored a series of full scale dwelling tests in 1979 in Los Angeles, CA [54;55] to determine the performance requirements for newly developed residential sprinkler technology (RTI 41). The tests were conducted in a large, two story dwelling which was instrumented to measure the development of hazardous conditions in the rooms and along the escape routes.

While no data were obtained on detector response in the Los Angeles test series, extensive data were collected on gas temperatures and toxic gas production - both before and after sprinkler activation. Peak levels for eye level temperatures, carbon monoxide and oxygen concentration (table 2) indicate that hazardous conditions were not approached in the room of fire origin, at the top of the stairs, or in the bedroom on the second floor for both smoldering and flaming upholstered furniture fires initiated in the living room. The residential sprinkler responded before hazardous conditions were approached, successfully extinguishing the fire and maintaining tolerable levels of temperature, $\mathrm{CO}$ and $\mathrm{O}_{2}$ in the room of origin, and throughout the dwelling.

The results from these living room upholstered chair fires are typical of the performance of the residential rapid response sprinklers for most of the 
scenarios tested. Two exceptions were (1) a flaming fire in an unsprinklered walk-in closet in a bedroom and (2) a smoldering fire in a closed bedroom. In both of these cases, a residential sprinkler was located in the bedroom. Comparison of ceiling gas temperatures for tests with and without a residential sprinkler installed in the closet (figure 17) indicate a dramatic difference in performance. In the test where the closet was sprinklered, minimal increases in temperature and $C O$ resulted throughout the dwelling. In the test where the closet was not sprinklered, hazardous conditions were substantially exceeded in the bedroom, along the escape path, and in the living room. Table 3 provides a comparison of peak values.

In the smoldering mattress bedroom test where the bedroom door was left open, providing ventilation, the residential sprinkler extinguished the fire, and hazardous conditions were not approached. As indicated in figure 18, the sprinkler activated shortly after transition to flaming, which was accompanied by an increase in gas temperature at the sprinkler.

In the test where the bedroom door was left closed, the fire did not reach a flaming state. As a result, although the residential sprinkler eventually activated (more than five hours after smoldering ignition) and controlled the fire, Co concentrations exceeded $5000 \mathrm{ppm}$ (the maximum range of the CO analyser) more than two hours prior to sprinkler activation. Such a concentration for that time period would be considered lethal.

For the tests reviewed, residential sprinklers controlled flaming fires typical of many of those that occur in residences. In most of these typical scenarios, the sprinkler activated before hazardous conditons were reached in the room of fire origin and maintained tolerable conditions throughout the space. However, in some, such as unsprinklered flaming closet fires and smoldering fires, hazardous conditions were reached, even with the more rapid responding residential sprinklers.

\subsection{Health Care Room-Corridor Studies}

CFR conducted a full scale test program to evaluate the performance of detectors and sprinklers in hospital rooms. The tests were conducted in one 
of CFR's room-corridor facilities, and involved flaming ignition of mattresses (flaming fire scenario) and wardrobes (shielded fast flaming fire scenario), simulating fires in patient rooms adjacent to a corridor.

Detector studies [56] provided comparisons among lonization and photoelectric smoke detectors and heat detectors at different locations in terms of alarm times and avallable escape time. Figure 19 shows the average and the range of estimated avallable escape times (1) from the room of fire origin, and (2) along the escape path in the corridor for the complete series of burns. Consistent with previous work, it was found that smoke detectors provided the maximum escape time. Smoke detectors in the corridor provided three to four minutes of escape time from the room, and along the corridor. Heat detectors in the room provided an average escape time of one minute from the room and two minutes along the corridor. However, in some of the tests the hazardous threshold for smoke obscuration was reached in the room prior to activation of the heat detector.

0'Ne111, Hayes, and Zile conducted studies of sprinkler performance in the same facility [57]. The thermal response characteristics of both standard and residential sprinklers were examined. In tests with flaming ignition of mattresses, a simulated residential sprinkler activated prior to attainment of hazardous conditions, extinguished the fire, and maintained survivable conditions in the room of fire origin. However, in tests with the somewhat slower standard sprinkler, smoke concentrations exceeded the hazard threshold in the room, along the corridor, and in the remote lobby area prior to sprinkler activation. Figure 20 provides a comparison of the impact of the residential and standard sprinkler activation relative to attainment of hazardous conditions both in the room of fire origin and along the corridor. Figure 21 illustrates a substantial difference in the height of the smoke layer in the patient room doorway at the time of activation for the two sprinklers. For the standard sprinkler the smoke layer would have reached bed level. (This does not take into account the mixing effect of the sprinkler spray on the smoke distribution after initiation of suppression.)

In tests with combustible wardrobe fires, little difference was observed in the response time for the two sprinklers. Figure 22 1llustrates the rapid 
fire growth rate resulting from the shielded wardrobe fire. As would be expected, for such a rapidly developing fire, the relative difference in activation time between the residential and the slower standard sprinkler is smaller. However, test results indicated that hazardous conditions were reached at approximately head level ( $1.5 \mathrm{~m}$ above floor) in the room, corridor and lobby before either sprinkler activated.

These health care room-corridor studies indicate that for typical flaming fires (e.g., mattresses) a residential sprinkler can provide protection to occupants both inside and outside the fire room. A heat detector may provide marginal escape time in some instances, but smoke detectors provided superior performance, providing at least two minutes of escape time in all of the cases examined.

In the case of severe, fast flaming shielded fires such as those from burning wardrobes or unsprinklered closets neither a standard nor residential sprinkler would respond rapidly enough to prevent hazardous conditions from being reached throughout the space, and a heat detector would provide essentially no warning. Although no smoke detectors were present for the shielded wardrobe tests, the rapid development of the fire indicates that smoke detectors would provide marginal or no escape time, particularly from the room of fire origin. While these studies were directed at health care occupancies, the results are somewhat relevant to residential occupancies of similar geometry such as hotels, motels and apartments.

\subsection{Implications of Experimental Results for Residential Life Safety}

The results of these full scale studies provide some insight to the potential role of detection and sprinkler technologies on residential life safety. For example, smoke detectors installed in accordance with current practices (NFPA 74) virtually always provide substantial escape time. The amount of time is dependent on the geometry of the structure and the growth rate of the fire, but a minimum escape time from the room of fire origin of 
two minutes ${ }^{7}$ was usually exceeded under the conditions tested. Heat detectors located in the room of origin provided marginal escape time under some of the fire scenarlos tested, but demonstrated no apparent advantages over smoke detectors. For many fires, hazardous conditions were approached or exceeded before the heat detector activated. This was particularly true for smoldering fires.

Sprinkler systems can make an important contribution to residential life safety; namely they provide immediate action to control or extinguish the fire. This capability is particularly important when occupants are not able to escape, and therefore must be protected while remaining in the dwelling. In the studies reviewed, a standard sprinkler (RTI 100) controlled or extingulshed the developing fire, and usually provided escape time from locations outside the room of fire origin. However, for many of the fires, hazardous conditions were reached in the fire room prior to activation of a standard sprinkler, providing only marginal protection to occupants in the room.

Except for tests involving smoldering fires or unsprinklered flaming closet fires, the residential sprinkler (RTI 41) activated much earlier than the standard sprinkler, generally before hazardous conditions were reached in the room of fire origin. For many of these cases the fires were extinguished and survivability in the fire room appeared likely, unless the occupant was intimately exposed to the fire. In the fire tests involving unsprinklered closet fires and smoldering upholstered furniture fires, hazardous conditions were reached prior to operation of the residential sprinkler, resulting in limited 11 fe safety protection in the room of fire origin and along primary escape paths.

These full scale tests pointed out limftations in the impact of detectors and sprinklers for selected geometries and conditions. For example, in small volumes typical of mobile homes, ramblers, apartments and other single-story conventional residences, hazardous conditions develop throughout the communi-

\footnotetext{
${ }^{7}$ A number of the references selected two minutes as a minimum escape time needed for residences. This value is used here only for discussion purposes; the actual escape time needed depends on factors such as condition and mobility of the occupants and required travel distances to safety.
} 
cating spaces at nearly the same time. Therefore for such structures it may be necessary to assume that the entire volume is the room of fire origin in determining the required escape time and selecting a design strategy. The addition of a barrier such as a wall or closed door to provide physical separations within the residence can increase the escape time provided by a detector or sprinkler alone.

A smoldering fire in a closed room without a smoke detector presents a hazard to the occupants of the room. Smoke detectors installed in accordance with current criteria (typically located in halls and stairwells) will not activate before hazardous conditions are reached in a room with the door closed.

Finally, current installation criteria for residential sprinklers are intended to provide sprinkler coverage in rooms of most probable fire origin, as indicated by residential loss experience. Complete sprinkler protection of a dwelling including bathrooms and closets appears impractical from a design and economic standpoint. However, if a fire occurs in a space that isn't protected, it may result in a different, more demanding challenge on the sprinkler system. For example, in flaming tests in closets which were not sprinklered, hazardous conditions occurred along the escape path and in other rooms before the residential sprinkler in the adjacent bedroom controlled the fire. Therefore, reliance on a residential sprinkler to provide protection to occupants who can not escape would be inappropriate for these conditions.

Tables $4 \mathrm{a}, 4 \mathrm{~b}$, and $4 \mathrm{c}$ summarize the effect of detectors and sprinklers on the three fire types and various occupant locations and capabilities discussed in section 3. These estimates are based primarily on the results of the full scale studies reported here. Since heat detectors consistently provided less time for escape than smoke detectors, and frequently provided no escape time, they are not included. It should be noted that this paper addresses life safety from fires in habitable areas considered the most probable areas of fire origin. While heat detectors provided marginal or inadequate escape time for many of the cases studied, their use for protection of uninhabited areas, such as garages and attics, where temperature and humidity conditions vary substantially, is appropriate. 
For each combination of fire growth type and occupant status, an assessment is made of the ability of a residential smoke detector to provide at least two minutes of escape time, and a standard sprinkler or a residential sprinkler to activate and extinguish the fire prior to the development of conditions that wlll result in death or serfous infury to the occupant.

In table $4 \mathrm{a}$, assessments are provided for the likely 1mpact of smoke detectors and sprinklers on smoldering/flaming fires. For the analysis conducted, it was assumed that persons in the room of fire origin who were awake and moblle would react prior to detection of the fire by the smoke detector or extinguishment by the sprinklers, therefore reducing the need for these devices for this particular case. It is recognized that one can not accurately predict that correct behavior would result on the part of the occupant. In lieu of a detalled examination of this, in those cases where incorrect behavior would lead to a fatality, it is assumed that the occupant is actually immobile for purposes of this analysis.

Based on review of the results from the full scale studies included in this paper, it is expected that a smoke detector, a residential sprinkler or a standard sprinkler w1ll provide protection to mobile occupants outside the room of fire origin. Immobile occupants would be protected by either sprinkler; a smoke detector would have little benefit without rescue. For occupants located in the room of fire origin, the extent to which protection is provided is greatly influenced by their status. For example, a smoke detector would provide the minimum escape time for occupants in the room who are awake or asleep, but mobile. And, while a residential sprinkler responded before hazardous conditions were reached in the room of origin in some of the tests reviewed, this was not the case for the smoldering/flaming tests in mobile homes, or in the closed door bedroom tests. Therefore, it was concluded that residential sprinklers would provide some, but not complete protection for occupants in the room of fire origin who are exposed to a smoldering/flaming f1re. The test data suggest that the delay in response of the standard sprinkler to smoldering fires would result in hazardous conditions in the room of origin before inttiation of suppression, therefore providing little protection to occupants in the room. 
The assessments provided in table $4 \mathrm{~b}$ for flaming fires indicate similar protection to that for the smoldering/flaming condition for occupants outside the room. For occupants located in the room of fire origin, the test results indicate that the residential sprinkler would respond very quickly to this type of fire growth behavior, initiating suppression action before hazardous conditions were approached and protecting occupants in the room, regardless of their status. As in the case of the smoldering/flaming fire, awake/mobile occupants who might react irrationally - resulting in a fatality, were considered immobile.

Table $4 \mathrm{c}$ provides assessments of the impact of smoke detectors, residential sprinklers and standard sprinklers for fast flaming fires. The full scale tests in this review included rapidly developing shielded wardrobe and closet fires. The extremely limited data from these tests indicate that smoke detectors may provide limited protection to mobile occupants outside the room of origin. However, hazardous conditions were exceeded both in the room of fire origin and at multiple locations outside the room before either a standard or residential sprinkler would have responded. Also, due to the shielding of the fire from the sprinkler water spray, extinguishment was not always readily attained.

While the results indicate that detectors and sprinklers provide very limited benefit for the shielded fast flaming fires included in this study, the benefits may be considerably greater for other types of fast flaming scenarios. For example, Cote [58] reports rapid extinguishment of fast developing flaming fires initiated with various quantities of flammable liquids. These fires, conducted to simulate hotel arson/incendiary fires, resulted in marginally hazardous smoke conditions in the immediate area of the fire, but extinguishment by the residential sprinklers resulted in low temperature and toxic gas levels. This indicates that the assessments provided in table $4 \mathrm{c}$ should be primarily limited to shielded, rapidly developing fires. Significant benefits may be derived from both standard and residential sprinklers for other fast flaming scenarios such as flammabile liquid spill fires.

The tables illustrate our lack of data on the exposure of persons who are intimate with ignition. In addition, the experimental data indicate that none 
of these strateg1es w1ll protect occupants who are 1ntimately exposed to shlelded fast flaming fire, but some benefit may be expected in smoldering/flaming and flaming fires.

\section{QUALITATIVE ASSESSMENT OF DETECTOR AND SPRINKLER EFFECTIVENESS}

\subsection{Assessments}

The analysis of full scale test data presented in section 4 , and a review of residential fire 1088 experlence, can be used to estimate the potential effectiveness of detector and sprinkler technology in providing adequate life safety in residential occupancies. Also this assessment identifies limitations and gaps in avallable data.

The assignments in tables $4 \mathrm{a}, 4 \mathrm{~b}$ and $4 \mathrm{c}$ from section 4 were used to estimate the potential benefit of a smoke detector, a standard sprinkler, or a residential sprinkler in protecting against the dominant fatal scenarios for residential occupancles. Table 5 summarizes the results of this analysis.

The $81 \mathrm{x}$ dominant scenarlo groups 11 sted in table 5 represent those fatal fire scenar10s which most frequently occur in one and two family dwellings, moblle homes, and apartments. The data on scenarlo groups and fatallt1es were obtalned by analysis of the 1980-81 NFIRS data base [2].

The characteristics of the scenarlo groups correspond to the fire and occupant parameters discussed in section 3. Figure 23 1llustrates the spec1f1c parameters to be considered for scenario group \#1, based on the possible combinations developed in the parametric model presented in section 3 . The appropriate combinations also were identified for the remaining groups.

A strategy was considered to provide protection if, by 1 tself, it would most likely provide a sufficient level of safety to prevent a fatality under that particular scenario group. Some interesting observations can be made based on the Information presented in table 5. For scenar1o group \#, where mobile occupants died outside the room while asleep, a smoke detector 18 the 
most effective strategy if one is concerned with protecting these occupants from all three fire types (i.e., shielded fast flaming, flaming, smoldering/flaming). While detectors, standard sprinklers and residential sprinklers all can be expected to provide protection for flaming fires, some limitations exist in the protection provided by standard or residential sprinklers due to the delay in responding to smoldering/flaming and shielded fast flaming fires. This scenario group accounts for nearly half of the fatalities in one and two family dwellings and mobile homes.

For the six major fire scenario groups included in this study, table 5 indicates that a combination of smoke detectors and residential sprinklers could provide the maximum protection among the various combinations of smoke detector, standard and residential sprinkler examined. If it is assumed that the smoke detector and residential sprinklers are totally adequate and reliable, then the combination of smoke detectors and residential sprinklers could reduce fatalities by as much as 73 percent in dwellings (scenario groups 非, \#4, and \#5). Similar benefits could be derived for mobile homes and apartments. Due to the assumption of total adequacy and reliability, the 73 percent reduction in fatalities may represent an upper bound estimate.

While the largest impact would result from the combination of smoke detectors and residential sprinklers, other combinations could also provide significant impact. For example, it is estimated that standard sprinklers in combination with smoke detectors could reduce fatalities by as much as 57 percent in dwellings (scenario groups 非 and 非).

The second most frequent scenario group was 非, involving occupants who are intimately exposed to the fire. The lack of a detailed understanding of the effects of fires on occupants who are intimate with ignition, or the performance of a detector or sprinkler on a concealed space fire limit our ability to assess the protection provided by these strategies for such residential scenarios. But intuitively, one must assume that the performance characteristics of state-of-the-art detection and sprinkler technology would have very limited impact on such fire deaths. 
The limited test results avallable for shielded fast flaming fires Indicate that it is unlikely that smoke detectors or sprinklers will provide protection to occupants located in the room of fire origin. It would appear that scenar10 group 非, which 1ncludes the fewest number of fatal1t1es for the six major scenario groups, could not be adequately protected by any combination of these state-of-the-art smoke detectors and sprinklers. While this does not consider the impact of smoke detectors and sprinklers on fatalities from unshielded, fast flaming fires, the NFIRS Incident data base used to identify the major scenario groups included only a few fatalities resulting from such fires. The majority of the fatalities included in scenario group \#3 involved shielded fast flamming fires.

The results in table 5 for scenarlo groups \#1 and \#3 1ndicate that on the order of 20 to 30 percent of the fatalities in these residential suboccupancies may be unsavable by elther detectors or sprinklers.

The NFIRS data base contains only a limited number of fatal fire incidents for large residential occupancles such as dormitorles, hotels and motels, board and care, and Institutional. However, the majority of fatal f1re Incidents in these suboccupancles result in one or two deaths, with the dominant scenarios similar to those of dwellings, mobile homes, and apartments [2]. If it is assumed that detectors and sprinklers would perform in a similar manner in these suboccupancies, the same benefits could be expected. Also it is likely that detectors and sprinklers would decrease the number of multiple-fatality fires. While these fires occur very infrequently, they generally recelve a great deal of public attention.

\subsection{Limftations of the Assessments}

The results of the assessments in section 5.1 indicate that smoke detectors and residential sprinklers could have a significant impact on residential fire deaths. These results are based on analysis of a $11 \mathrm{mited}$ number of full scale experiments and statistical loss data from the NFIRS data base. The estimates are also based on the assumptions that the devices will be installed correctly, w1ll be maintained, and will perform adequately and reliably. 
The adequacy of the devices was partially based on analysis of the experimental studies. The extent to which these studies accurately reflect the universe of residential fire death incidents, and the validity of the extrapolations performed in the assessment can only be determined through more rigorous quantitative methods.

The reliability of detectors and residential sprinklers depends on factors such as the performance limits of the mechanical and electronic components, the installation, and adequate maintenance. In addition, environmental factors such as variation in hazard development (e.g., the effect on smoke generation and transport) or variations in system parameters (e.g., changes in system water pressure) can potentially alter the reliability or adequacy of the device.

Finally, in addition to considerations regarding adequacy and reliability, the assessment excludes any considerations of cost/benefit, or social issues such as individual risk perception and acceptability of the technology. These factors, while beyond the scope of this paper, are essential in successful implementation of any strategy to improve fire safety.

\section{TOWARD APPLICATION OF QUANTITATIVE TECHNIQUES}

Quantitative measures of the performance of detectors or sprinklers under varying conditions would improve the estimates presented in table 5 . This can be done using analytical models which mathematically describe the function of these systems for a broad range of cases, and a series of carefully planned and executed experimental studies to validate the models and test their results.

NBS has been engaged in research to develop analytical methods to predict room fire growth, and multiple room fire spread [59,60]. An extension of these efforts that will provide the quantitative basis for determining the performance of detectors or sprinkler systems in residential fires has recently been initiated. The objective of this work is to provide analytical methods useful in increasing the ability to predict effectiveness of these systems in reducing residential deaths and injuries. This broader context 
includes consideration of occupant needs, hazard development, and the performance of other fire safety strategles as well as detectors or sprinklers. This approach requires an understanding of the physical processes involved and their functional interdependencies.

A parametric framework or model is under development at NBS which can assist in addressing residential life safety from this broad, comprehensive viewpoint. The initial version of this model (figure 24), while incomplete, identifies many of the conditions or factors to be considered for residential Iife safety, including detection and suppression. The model, though broad in context, has not been sufficiently developed to identify the functional interdependencies of many of these factors. At this stage in its development, the model is helpful in 1dentifying key elements or factors and developing an understanding of the specific elements associated with detection and suppression. Future efforts will extend the model to sufficient detall to permit formulation of analytical expressions for evaluation of the functional interdependencies. This will lead to the ability to predict performance for specific conditions of hazard development, occupant behavior and fire safety strategy.

The model in figure 24 is consistent with the expression proposed by Cooper (see section 3) for time required for escape/rescue. Within the context of this framework, Cooper's expression can be recast as follows: Life safety can be assured in a residential fire if

$$
T_{m s}=\left(T_{H}-T_{D}\right)-T_{E, R} \geq 0
$$

where

$$
\begin{aligned}
& \mathrm{T}_{\mathrm{ms}}=\text { margin of safety (time) } \\
& \mathrm{T}_{H}=\text { time to hazard } \\
& \mathrm{T}_{\mathrm{D}}=\text { time to detection } \\
& \mathrm{T}_{\mathrm{E}, \mathrm{R}}=\text { time to escape/rescue }
\end{aligned}
$$

This expression simply states that the time available $\left(\mathrm{T}_{\mathrm{H}}-\mathrm{T}_{\mathrm{D}}\right.$ ) must be greater than or at least equal to the time required $\left(T_{E, R}\right)$ for occupant escape or rescue; that $1 \mathrm{~s}, \mathrm{~T}_{\mathrm{ms}} \geq 0$. If the occupant must be protected in place, then 
hazardous levels must not be reached. Figure 25 provides a graphical illustration of the hazard development and occupant escape/rescue processes which relate to the above expression. The objective $\mathrm{T}_{\mathrm{ms}} \geq 0$ can be met by application of a number of strategies, including early warning detection (reduce $\mathrm{T}_{\mathrm{D}}$ ), control of hazard development (increase $\mathrm{T}_{\mathrm{H}}$ ) or by adjusting the needs of the occupants $\left(T_{E, R}\right)$. The adequacy of each of these strategies, alone or in some combination, for specific conditions must be determined.

Each of the parameters in the above expression involves the interaction of elements along major paths in the model (figure 26). The model identifies the logical relationships of the elements. However, analytical expressions for the various functional elements and their interdependencies remain to be developed.

Ongoing research at NBS is directed at doing this. It involves both theoretical and experimental research to examine the appropriate elements in the model leading to an ability to predict whether or not the objective $\left(T_{m s} \geq 0\right)$ has been met for specific cases. Attention is being given to developing methods of predicting the performance of smoke detectors and residential sprinklers within this context.

Current knowledge of the processes involved in detection and sprinkler suppression is limited, but important progress has been made in recent years. Work by Alpert [44] and Heskestad [61] provide a basis for predicting thermal response of sprinklers exposed to heated ceiling jets for unconfined ceilings typical of large, open rooms such as warehouses. Recent work by Evans [47] has extended this work to small compartments where limited experimental results indicate that the ceiling jet may be directly influenced by the formation of a high temperature zone in the upper part of the room early in a fire. While this extension appears promising, further study and validation is necessary to provide a generalized form of calculation compatible with stateof-the-art analytical fire growth models.

Generalized quantitative expressions for extinguishing agent effects on residential compartment fires are not available. Fire extinguishment involves a very complicated interaction of physical and chemical processes, including 
agent particle size formation, particle transport to combustion surfaces, and the effects of the delivered agent on burning rate, combustion gas generation, and environmental conditions within the space. Early work by Rashbash [62] and Magee and Reitz [63] provided limited empirical correlations for water spray effects on burning fuels. These studies demonstrated that extinguishing agent effects on burning rate were influenced by individual droplet size as well as the quantity of agent, and the burning characteristics, geometric arrangement and ventilation conditions associated with the fuel.

Ongoing work by Milke [64] at NBS is directed at extending these efforts to identify extinguishment thresholds in terms of mean droplet diameter and quantity for water sprays. Additional ongoing work by $\operatorname{Prahl}^{8}$ on development of scaling laws for application in developing experimental correlations for water droplet formation and initial trajectory, and Alpert [65] on the interaction of fire plumes and water sprays, will aid progress toward analytical methods for evaluating sprinkler effectiveness for residential rooms.

Finally, there are no current methods that enable one to determine the effects of other fire safety design features on sprinkler effectiveness. Historically many designers have assumed that the effect of multiple design elements is at least additive if not synergistic, but recent experimental work suggests that this may not always be true. For example, in tests conducted by the Illinois Institute of Technology Research Inst1tute (IITRI) in 1978 [66] it was demonstrated that smoke operated automatic door closers in conjunction with automatic sprinklers provided excellent protection in areas outside the fire room. However, by closing the door to the fire room, hazardous conditions were reached much sooner in the room of fire origin, often before the sprinkler responded.

Ongoing and future research at NBS is intended to provide generalized expressions for detector and sprinkler activation and water spray effects on compartment fires, and result in engineering methods for detection and sprinkler design effectiveness. These efforts should reduce the gaps and limita-

\footnotetext{
${ }^{8} \mathrm{Dr}$. Joseph Prahl (Case Western Reserve University) has recently initiated a study to develop scaling laws for water droplet formation and initial trajectory. This work is being performed under a grant from NBS/CFR.
} 
tions inherent in the qualitative approach presented in this study, and identify areas for improvement in detection and suppression technologies.

\section{SUMMARY AND CONCLUSIONS}

The largest number of annual fire fatalities in the United States occurs in residential occupancies. Smoke detectors and sprinklers can have a large impact in reducing residential fatalities. These devices can be used in retrofit and new construction. As already indicated by various studies, nationwide use of smoke detectors, installed in accordance with the location and audibility requirements in the NFPA Standard for Installation of Household Fire Warning Equipment (NFPA 74), alone could reduce the residential fire fatality rate by nearly 50 percent. An even larger potential impact would result from the combined use of smoke detectors and sprinklers ${ }^{9}$. Assuming reliability of the devices and applicability of limited full scale test results, combined use of smoke detectors and residential sprinklers could reduce fatalities on the order of 73 percent for one and two family dwellings, mobile homes, and apartments. Standard sprinklers in combination with smoke detectors could provide a 57 percent reduction for the scenarios examined. Similar benefits appear possible for larger residential occupancies such as dormitories, institutions, hotels and motels.

Approximately 20 to 30 percent of the fatalities in residential occupancies appear unsavable by current smoke detector or sprinkler technology. These fatalities occur primarily due to intimate exposure of the individual to the fire, or exposure to a very rapidly developing shielded fire. In both cases, hazardous conditions frequently occur prior to smoke detector or sprinkler activation.

The predicted reduction in fatalities is based on certain assumptions since the costs and practicability of these devices have not been assessed; full assessments have not been made of the limitations of these technologies,

\footnotetext{
${ }^{9}$ The 1980 edition of NFPA 13D, Standard for the Installation of Sprinkler Systems in One and Two-Family Dwellings and Mobile Homes anticipates the installation of smoke detectors in accordance with NFPA 74 in addition to a residential sprinkler system.
} 
nor have their performance, system adequacy and rellab1lity been evaluated; fallure thresholds for significant variations in environmental conditions such as supply water pressure, maximum furnishing fuel load, etc. have not been determined; and avallable experimental data can not be generalized to all residential occupancies or fire scenar1os.

These IImitations stem from Inadequate knowledge of the physical processes involved. Therefore NBS has initiated research to provide an understanding of these processes, and to develop analytical techniques for quant1tative predictions.

An initial model has been developed which 1dentifles key factors in providing residential 11 fe safety. A simple mathematical expression has been adapted as a success criterion, and research 18 ongoing at NBS to address specific parameters in the expression. Future efforts will be directed at extending the model to sufficlent detall to provide the basis for examining the functional interdependencles among key factors. Initially, the focus of this work is on modeling detection and extinguishment of residential fires.

Benefit/cost analyses are being performed at NBS to assess the relative effectiveness of state-of-the-art detector or sprinkler technologies in residential occupancies. While performance of these devices is important in meeting the success criterion, the cost to implement these strategies also is relevant.

Analytically based models and benefit/cost analysis techniques w11 provide a means for development, design, selection and performance evaluation of fire safety strategles for residential life safety, including the use of automatic detection and suppression. Specific cases can then be evaluated to determine the optimum design strategy (e.g., automatic detection, or automat1c detection with compartmentation) on the basis of (1) hazard development, (2) occupant conditions, (3) fire safety performance, and (4) economic impact. 


\section{ACKNOWLEDGMENTS}

Special appreciation 18 extended to the following individuals for assisting in the review of this paper and providing valuable comments:

Dr. H. Adams, Technical Director, Man-Made Fiber Producers Association, Inc.

Mr. Irwin A. Benjamin, Benjamin-Clarke Assoclates, private engineering consultant.

Mr. Arthur E. Cote, Assistant Vice President of Engineering and Technical Services, National Fire Protection Association.

Mr. Russell P. Fleming, Vice President of Engineer1ng, National Fire Sprinkler Association.

Mr. E. T. Kubu, Manager of Government-Industry Llaison, Allied Corporation.

Mr. Tony Shaw, Chalrman, Man-Made Flber Producers Assoclation Technical Committee and Manager of Technical Information, Hoechst Fibers Industries.

In addition, the author would like to thank Mr. Harold E. Nelson of the Center for Fire Research and Allan I. Gomberg of Firepro, Inc. (formerly with the Center for Fire Research) for their guidance and recommendations in structuring the analysis and providing fire fatality incident data.

\section{REFERENCES}

[1] America Burning, The Report of the National Commission on Fire Prevention and Control, U.S. Government Printing Office, May 1973.

[2] Fire in the United States, Fourth Ed1t1on, Federal Emergency Management Agency, Washington, D.C. 20472, 1981, p. 6 .

[3] Un1form Cod1ng for Fire Protect1on, 1976, NFPA No. 901, National Fire Protection Association, Quincy, MA 02269, 1976. 
[4] Fire Protection Handbook, 15th Ed., National Fire Protection Association, Quincy, MA 02269, 1981, pg. 15-25.

[5] Custer, Richard L.P. and Bright, R1chard G., Fire Detection: The Stateof-the-Art, National Bureau of Standards (U.S.), NBS TN 839, June 1974.

[6] Operation School Burning No. 2, National Fire Protection Association, Quincy, MA 02269, 1961.

[7] Standard for Installation, MaIntenance and Use of Household Fire Warning Equipment, NFPA 74, First Ed., National Fire Protection Association, Quincy, MA 02269, 1967.

[8] Residential Smoke and Fire Detector Coverage in the United States: Federal Emergency Management Agency - 1982 Survey (contract no. EMW-C0638), 1982 .

[9] Hall, John R, et al., Fire Code Inspections and Fire Prevention: What Methods Lead to Success?, National Fire Protection Assn., Boston, MA, 1979.

[10] Fire in the United States, Fourth Edition, Federal Emergency Management Agency, Washington, D.C. 20472, 1981, p. 25.

[11] Fire Performance Evaluation of the Federal Mobile Home Construction and Safety Standard, Report of the U.S. Department of Housing and Urban Development, Washington, U.S. Fire Administration, 1980, p. 11.

[12] Schaenman, Philip S. and Herrin, Cheryl L., Evaluation of Mobile Home Fire Safety: 1979-1980, prepared for the U.S. Department of Housing and Urban Development, Tri Data, Arlington, VA 22209, March 1982.

[13] Dana, Gorham, Automatic Sprinkler Protection, 2nd Edition, Wiley, New York, 1919.

[14] Standard for the Installation of Sprinkler Systems, NFPA 13, 23rd Edition, National Fire Protection Assn., Boston, MA, 1929.

[15] Bryan, John L., Automat1c Sprinklers and Standp1pe Systems, National Fire Protection Assn., Quincy, MA, 1980.

[16] Yao, Cheng, Application of Sprinkler Technology, presented at Workshop Engineering Applications of Fire Technology, National Bureau of Standards, Galthersburg, MD, Apr11 16-18, 1980, Factory Mutual Research, Norwood, MA 02062, March 1980.

[17] Bryan, op. c1t. pg. 62 .

[18] Standard for Installation of Sprinklers in One and Two Family Dwellings and Mobile Homes, NFPA 13D, First Edition, National Fire Protection Association, Quincy, MA 02269, 1975. 
[19] Kung, Hsiang-Cheng, Residential Sprinkler-Protection Study, prepared for National Bureau of Standards, Factory Mutual Research, (FMRC 非2442), Norwood, MA 02062, November 1975.

[20] Henderson, Norman C., Patton, Richard M., and Larcomb, D. Bruce, Investigation of Low-Cost Residential Sprinkler Systems, prepared for National Fire Prevention and Control Admin. (U.S.), Battelle Memorial Institute, June 1978.

[21] Standard for Installation of Sprinklers in One and Two Family Dwellings and Mobile Homes, NFPA 13D, 2nd Edition, National Fire Protection Assn., Quincy, MA 02269, 1980.

[22] Kung, Hsiang-Chang, et al., Sprinkler Performance in Residential Fire Tests, prepared for Federal Emergency Management Agency, U.S. Fire Administration 79019, Factory Mutual Research, Norwood, MA 02062, December 1980.

[23] O'Neil1, John G., Fast Response Sprinklers in Patient Room Fires, Fire Technology, Vol. 17, No. 4, November 1981, pp. 254-274.

[24] Report of Congress on Fire Protection Systems: Detectors, Remote Alarm Systems, and Sprinklers, prepared by Federal Emergency Management Agency, Washington, D.C. 20472, June 1981 .

[25] Federal Fire Experience for Fiscal Year 1963, Washington, Federal Fire Council, 1964, p. 26.

[26] Thomas, E. P., The Widget in the Ceiling, Navy Lifeline, September/October 1979 , p. 12 .

[27] Automatic Sprinkler System Performance and Reliability in United States Department of Energy Facilities 1952-1980, U.S. Department of Energy, DOE/EP-0052, Washington, D.C. 20545, June 1982 .

[28] Marryatt, H. W., Automatic Sprinkler Performance in Australia and New Zealand: 1886-1968, Australian Fire Protection Assn., Melbourne, Australia, 1971 .

[29] Fire Protection Handbook, 15th Edition, National Fire Protection Assn., Quincy, MA 02269, 1981, pg. 17-3.

[30] McGuire, J. H. and Ruscoe, B. E., The Value of a Fire Detector in the Home, Fire Study No. 9, National Research Council of Canada, December 1962 .

[31] Gomberg, A. and Offensend, Fred L., A Decision Model for Evaluating Residential Fire-Risk Reduction Alternatives, National Bureau of Standards, in preparation.

[32] Stickney, C. Walter, Oregon Life Safety Study of Institutional Care Facilities, TR 74-3, Society of Fire Protection Engineers, Boston, MA 02110. 
[33] St1efe1, S. W. and Gomberg, A., Life Saving Potential for Automat1c Sprinkler Systems in Nursing Homes, National Bureau of Standards, NBSIR in preparation, pg. 11 .

[34] 1979-80 NFIRS Data Base, unpublished computer data base.

[35] Cote, A. E. and Moore, D. A., Field Test and Evaluation of Resident1al Sprinkler Systems - Los Angeles Test Serles, presented to the NFPA 13D Subcommittee, Apri1 7, 1980, National Fire Protection Assn., Quincy, MA 02269 .

[36] Cote, Arthur E., Fleld Test of a Retrofit Sprinkler System, National Fire Protection Research Foundation, Washington, D.C. 20024.

[37] Babrauskas, V., Combustion of Mattresses Exposed to Flaming Ignition Sources, Part 1 - Full Scale Tests and Hazard Analys1s, National Bureau of Standards (U.S.), NBSIR 77-1290, September 1977.

[38] Budnlck, Edward K., Moblle Home Living Room Fire Studies: The Role of Interlor Finlsh, Natlonal Bureau of Standards (U.S.), NBSIR 78-1530, September 1978 .

[39] Kimmerle, G., Aspects and Methodology for the Evaluation of Toxicological Parameters during Fire Exposure, J. of Fire and Flammability/Combustion Toxicology, Vol. 1, 4-51, February 1974.

[40] Claudy, W. D., Resplratory Hazards of the Fire Service, National Fire Protection Assn., Quincy, MA 02269.

[41] Stewart, R. D., et al., Experimental Human Exposure to High Concentrations of Carbon Monoxide, Arch. Environ. Health, Vol. 26, 1-7, January 1973.

[42] Jin, T., Visibility through Fire Smoke, Part 2, Report of the Fire Research Institute of Japan, No. 33, 31-48 (1971). Part 5, Report of F1re Research Institute of Japan, No. 42, 12-18 (1975).

[43] Gomberg, Alan, Buchbinder, Benjamin and offensend, Fred J., Evaluating Alternative Strategles for Reducing Residential Fire Loss - The Fire Loss Model, National Bureau of Standards, NBSIR 82-2551, August 1982.

[44] Alpert, R. L., Calculation of Response Time of Celling-Mounted Fire Detectors, F1re Technology, August 1972.

[45] Heskestad, G., Investigation of a New Sprinkler Sensitivity Approval Test: The Plunge Test, Technical Report, FMRC 22485, Factory Mutual Research Corp., Norwood, MA, December 1976.

[46] Heskestad, G. and Delichatsios, M. A., Environments of Fire Detectors Phase I: Effect of Fire Size, Celling Height and Material, NBS-GCR-7795, National Bureau of Standards (U.S.), prepared by Factory Mutual Research, July 1977. 
[47] Evans, David D., Plume Flow in a Two-Layer Environment, presented at 21 st National Heat Transfer Conference, Seattle, WA, July 24-28, 1983.

[48] Cooper, Leonard Y., A Mathematical Model for Estimating Ava1lable Safe Egress Time in Fires, Fire and Materials, Vol. 6, Nos. 3 and 4, September/December 1982, pp. 135-144.

[49] Budnick, Edward and Klein, David, Mobile Home Studies: Summary and Recommendations, National Bureau of Standards (U.S.), NBSIR 79-1720.

[50] Budnick, Edward, Mobile Home Living Room Fire Studies: The Role of Interior Finish, National Bureau of Standards (U.S.), NBSIR 78-1530, September 1978, pg. 2 .

[51] Heskestad, G., The Sprinkler Response Time Index (RTI), presented at Technical Conference on Residential Sprinkler Systems, April 28-29, 1981, Factory Mutual Research, Norwood, MA 02062.

[52] Bukowski, Richard W., Investigation of the Effects of Heating and Air Conditioning on the Performance of Smoke Detectors in Mobile Homes, National Bureau of Standards (U.S.), NBSIR 79-1915, October 1979.

[53] Bukowski, R. W., Waterman, T. E. and Christian, W. J., Detector Sensitivity and Siting Requirements for Dwellings, National Bureau of Standards (U.S.), NBS-GCR-75-51, 1975.

[54] Kung, Hsiang-Cheng, et al., Field Evaluation of Residential Prototype Sprinkler - Los Angeles Fire Test Program, Factory Mutual Research FMRC J.I. OEOR3.RA(1), Norwood, MA 02062, February 1982.

[55] Cote, Arthur E., Final Report on Field Test and Evaluation of Residential Sprinkler Systems, National Fire Protection Association, Quincy, MA 02269, December 1982.

[56] Bukowski, Richard W., Test on the Performance of Automatic Fire Detectors in Health Care Occupancies: A Preliminary Report, National Bureau of Standards (U.S.), NBSIR 79-1739, April 1979.

[57] 0'Neil1, John G., Hayes, Warren D. and Zile, R. H., Ful1-Scale Fire Tests with Automatic Sprinklers in a Patient Room: Phase II, National Bureau of Standards (U.S.), NBSIR 80-2097, July 1980.

[58] Cote, Arthur E., Final Report on Field Test of a Retrofit Sprinkler System, National Fire Protection Research Foundation, Washington, D.C. 20024 , February 1983.

[59] Quintiere, J. G., Steckler, K. D. and McCaffrey, B. J., A Model to Predict the Conditions in a Room Subject to Crib Fires, First Specialists Meeting (International) of the Combustion Institute, University of Bordeau, France, July 20-25, 1981, Proceedings, The Combustion Institute, 1981 .

[60] Tanaka, T., A Model of Multiroom Fire Spread, National Bureau of Standards (U.S.), NBSIR 83-2718. 
[61] Heskestad, G., Physical Modeling of Fire, Journal of Fire and Flammab1lity, Vol. 6, pp. 253-273, July 1975.

[62] Rashbash, D. J., The Extinction of Fires by Water Sprays, Fire Research Abstracts and Reviews, 4, 28, 1962.

[63] Magee, R. S. and Re1tz, R. D., Extinguishment of Radiation Augmented Plastics Fires by Water Sprays, 15th International Symposium on Combustion, Combustion Institute, p. 337, 1975.

[64] Milke, J. A., Preliminary Investigation of the Thermophysical Effects of Water Sprays on Burning Solids, National Bureau of Standards (U.S.), in preparation.

[65] Alpert, R., Calculated Interaction of Sprays with Large-Scale, Buoyant Flows, presented at ASME Winter Annual Meeting, Phoenix, Arizona, November 14-19, 1982.

[66] Mniszewsk1, K. and Waterman, T. E., Effects of Open Doors on Sprinkler Effectiveness in a Patient Room, Final Report No. J8299-1, I111no1s Institute of Technology Research Inst1tute, June 1978. 

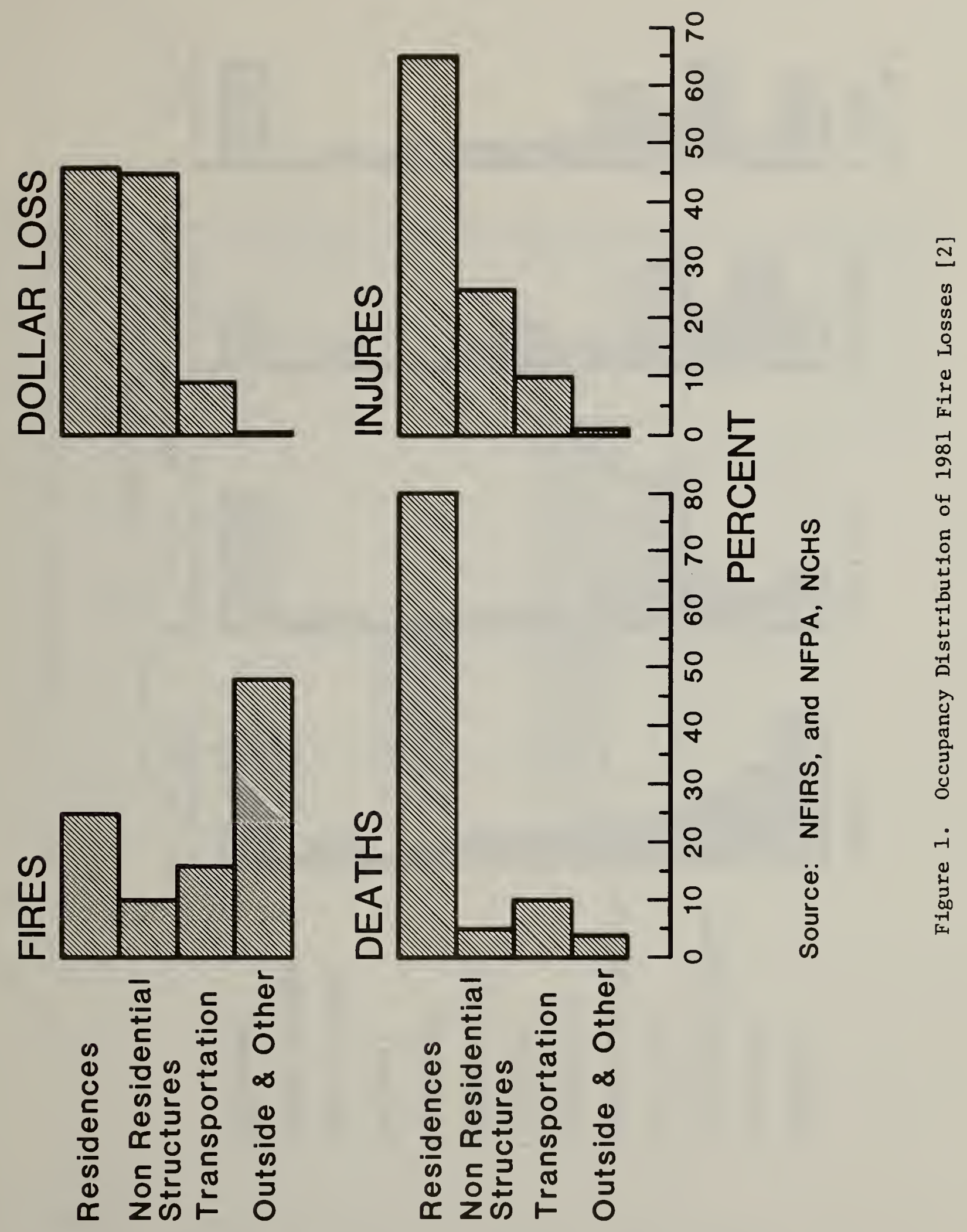

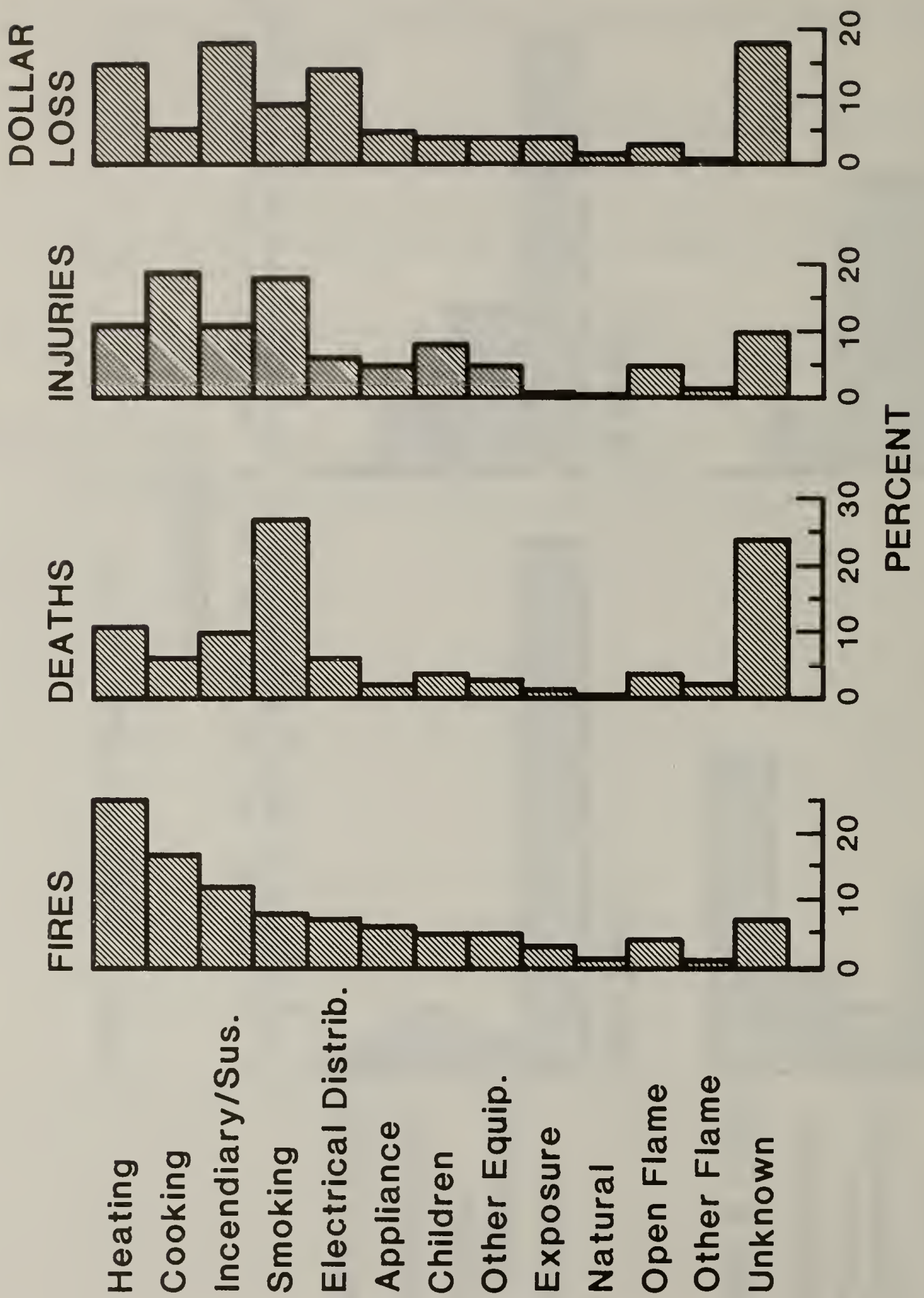


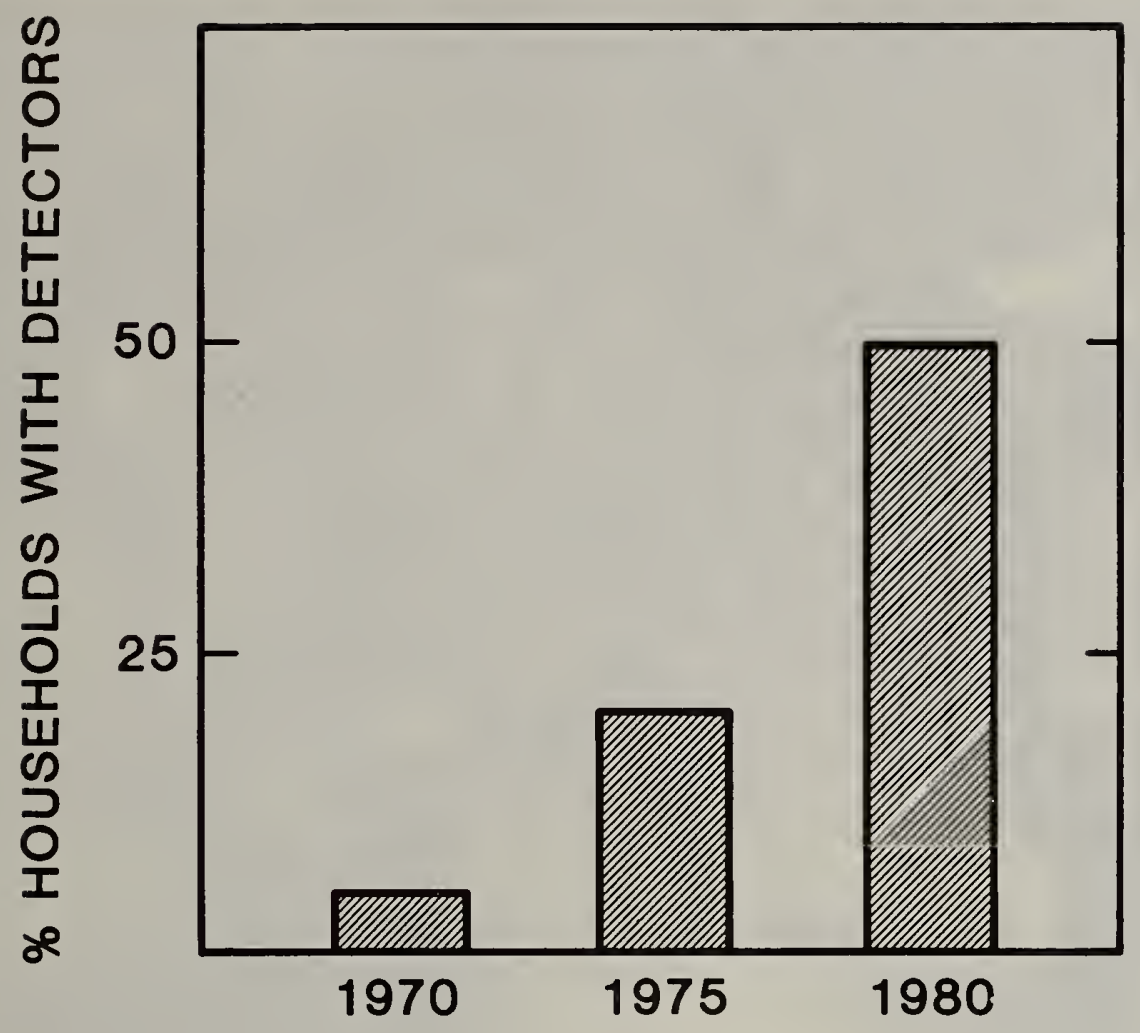

Figure 3. Growth of Smoke Detector Usage in Single Family Dwellings [8] 


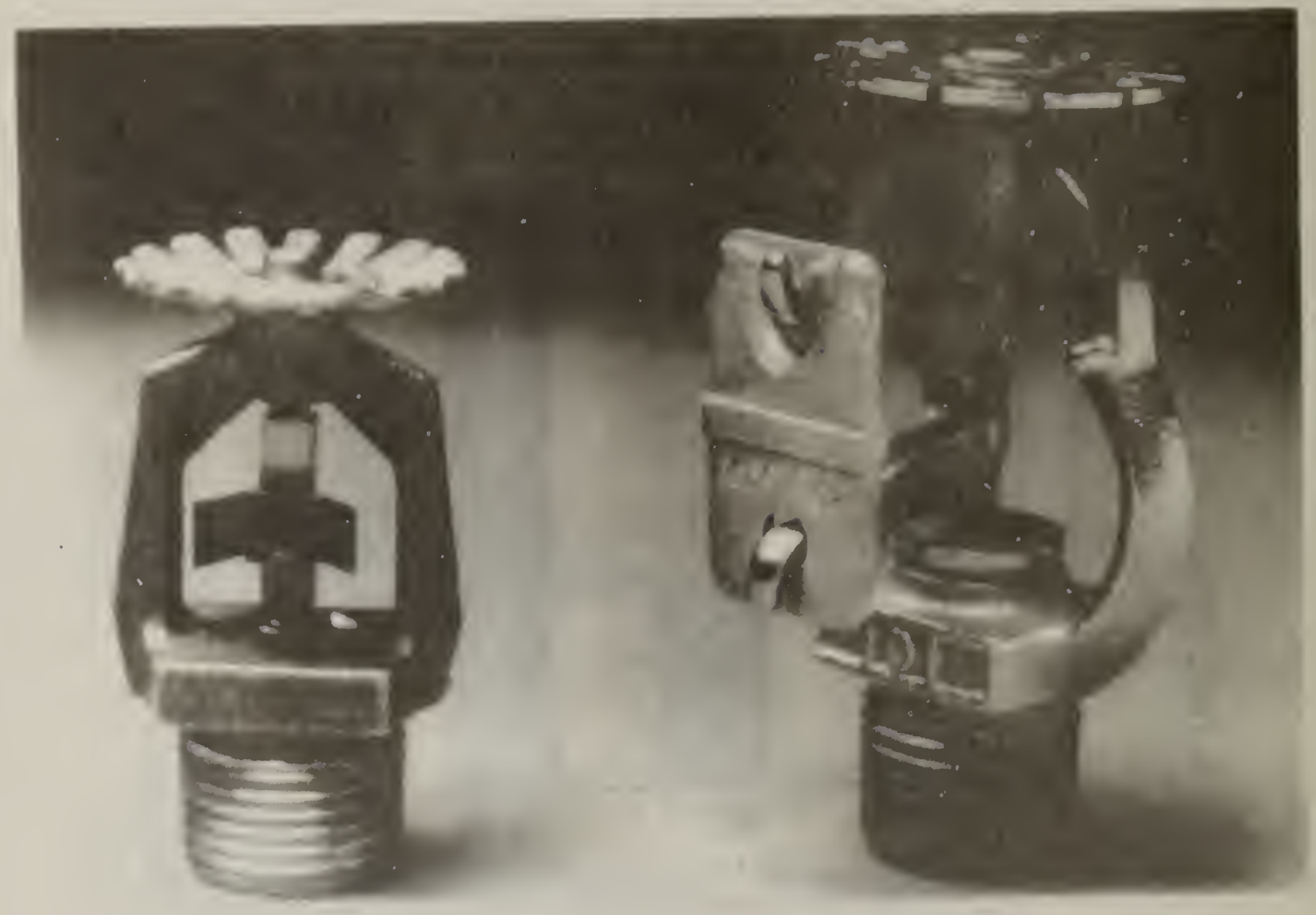

Figure 4. Typical Standard Sprinkler Head and Residential Sprinkler Head Demonstrating Significant Reduction in Thermal Link Mass for Residential Sprinkler Technology 


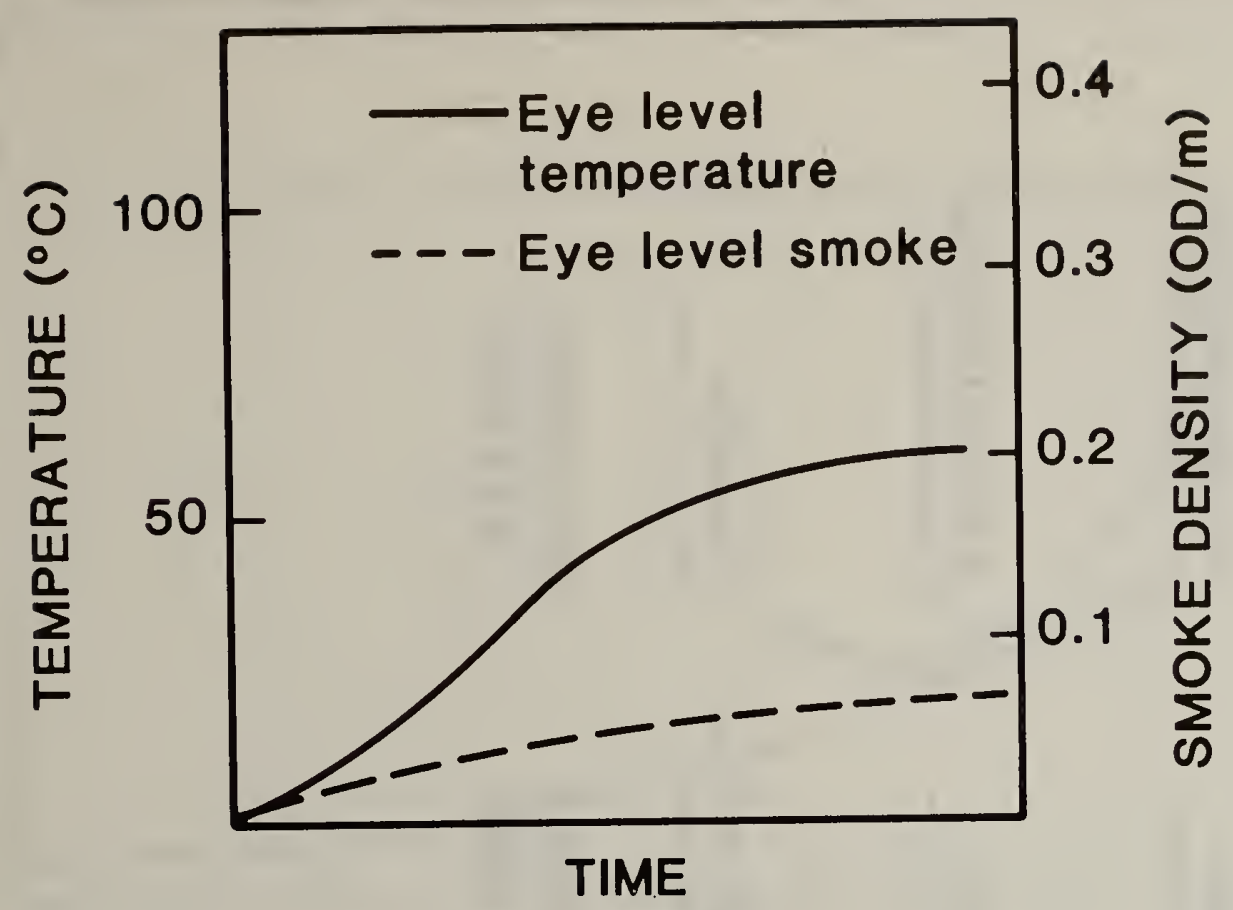

Figure 5. Eye Level Temperature and Smoke Density in Room of Fire Origin where Residential Sprinkler Controlled the Fire [54]

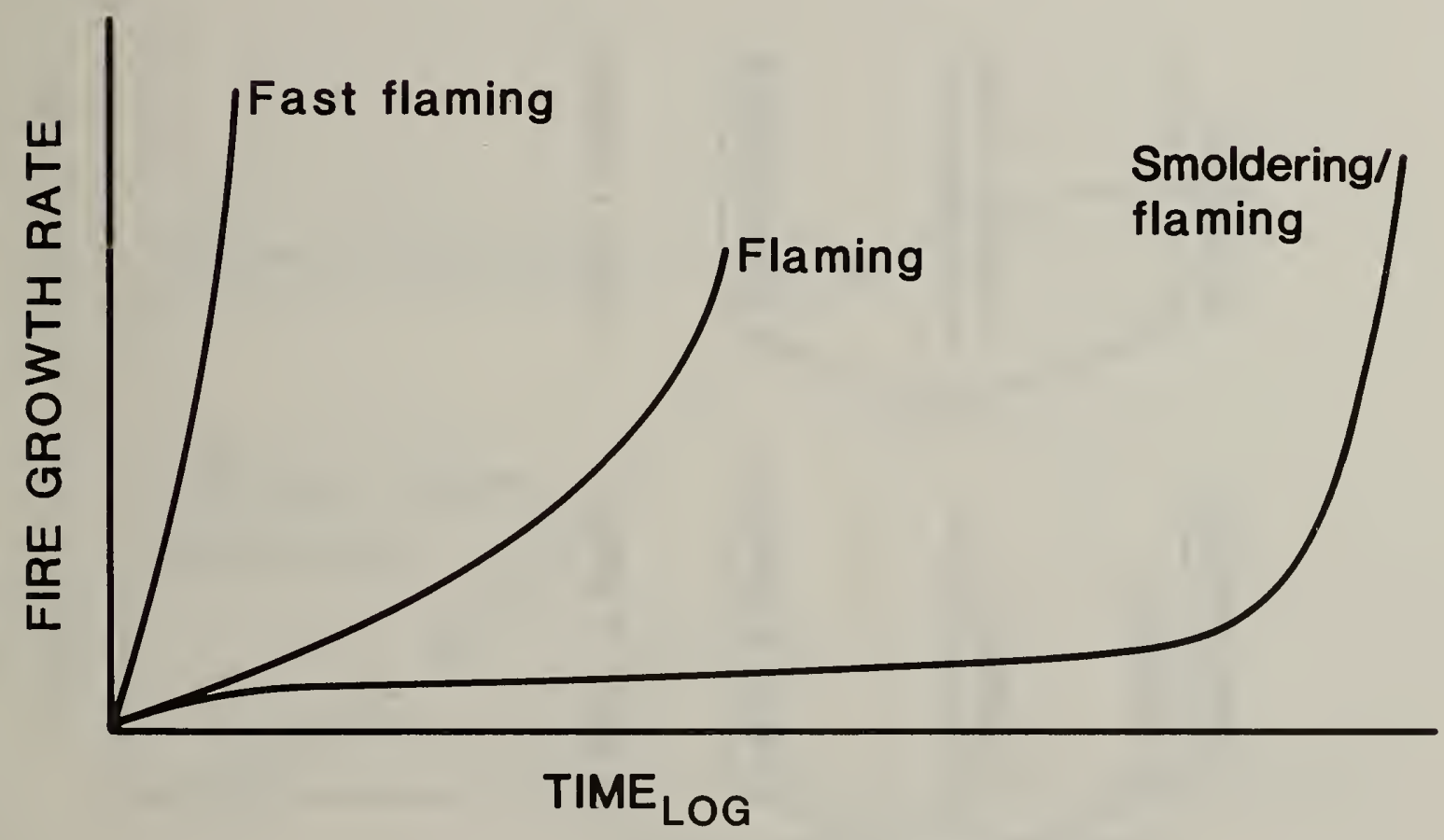

Figure 6. Illustration of Characteristic Residential Compartment Fires 

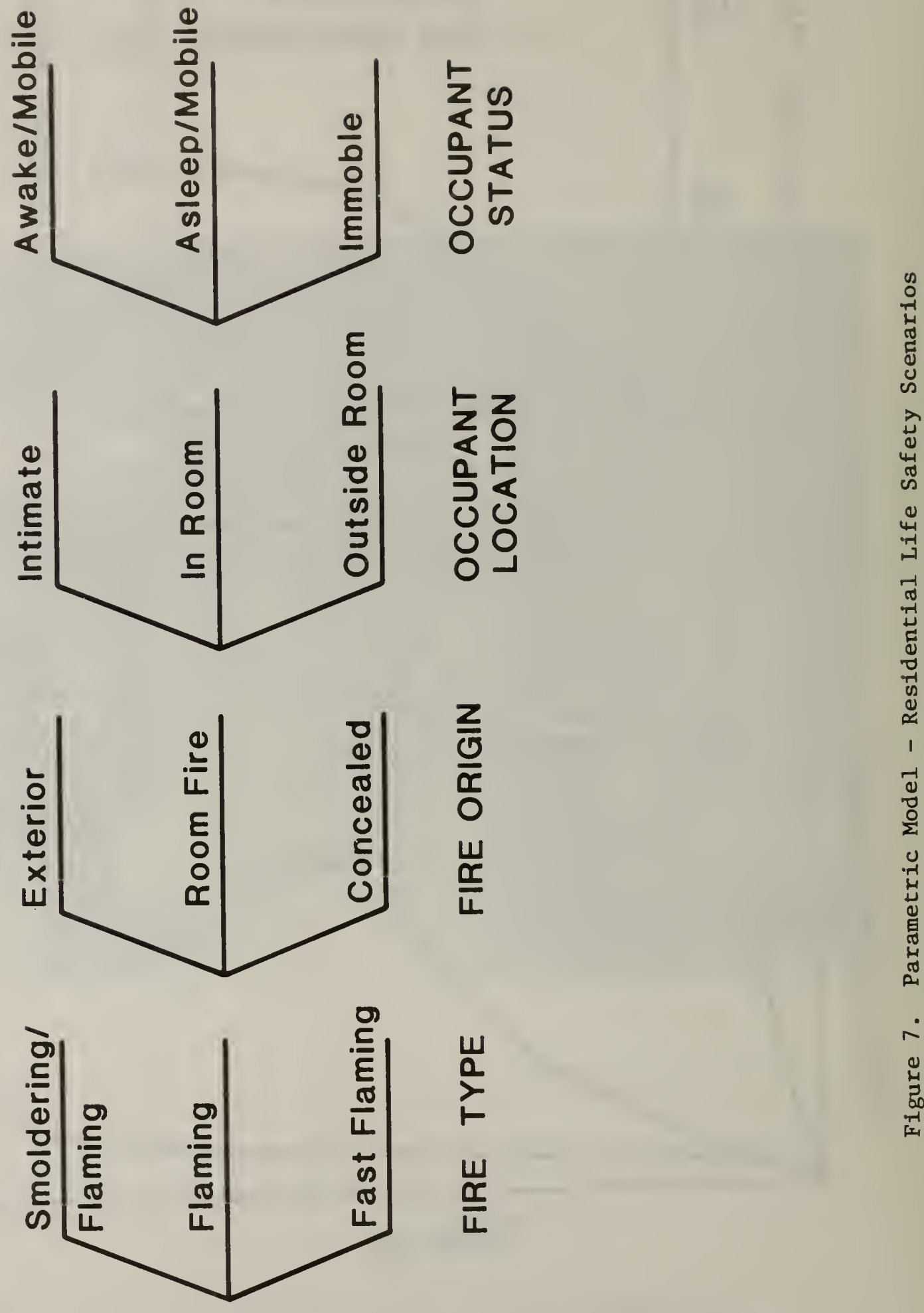


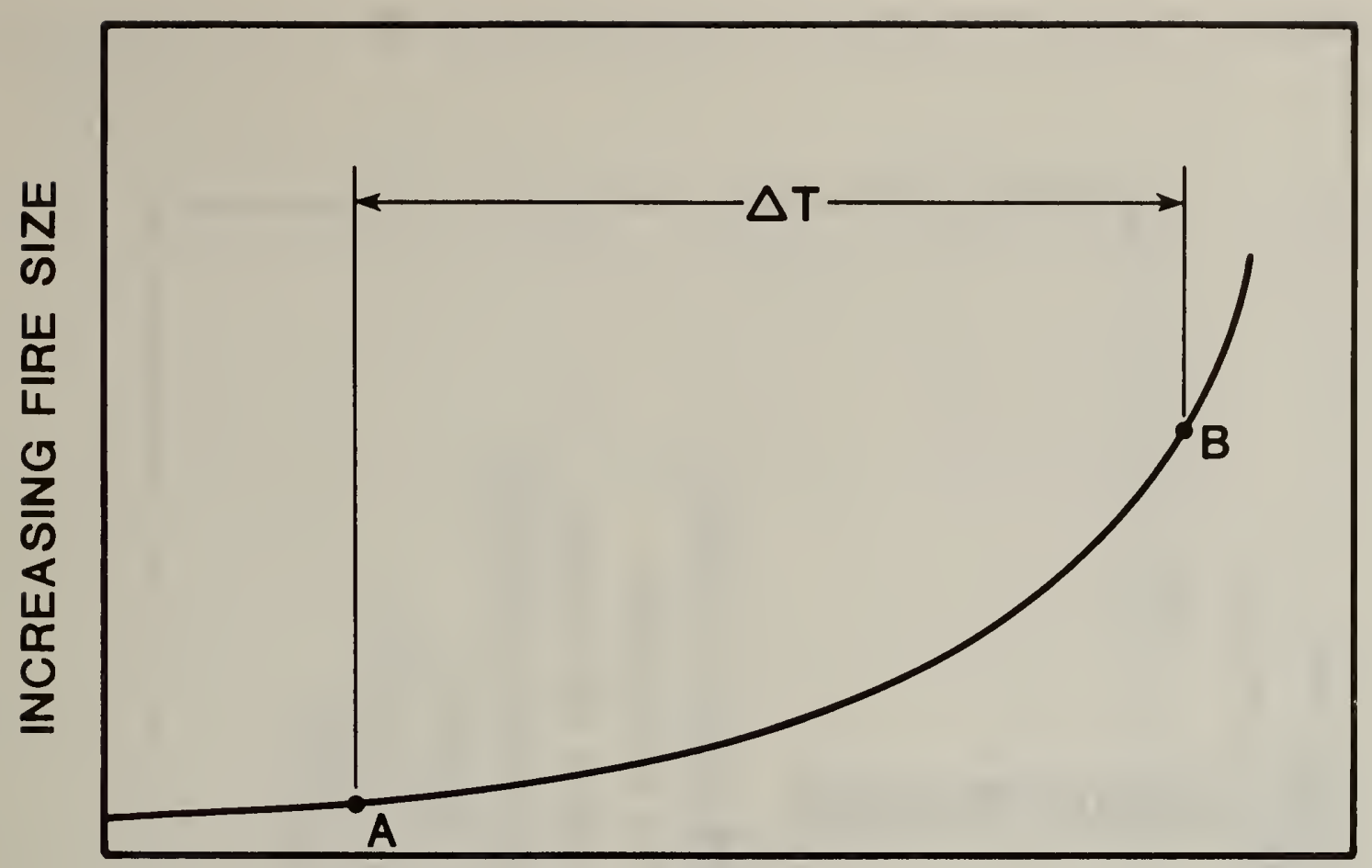

TIME

Figure 8. Comparison of Activation Times for Smoke Detector (A) and Sprinkler (B) for Typical Compartment Fire

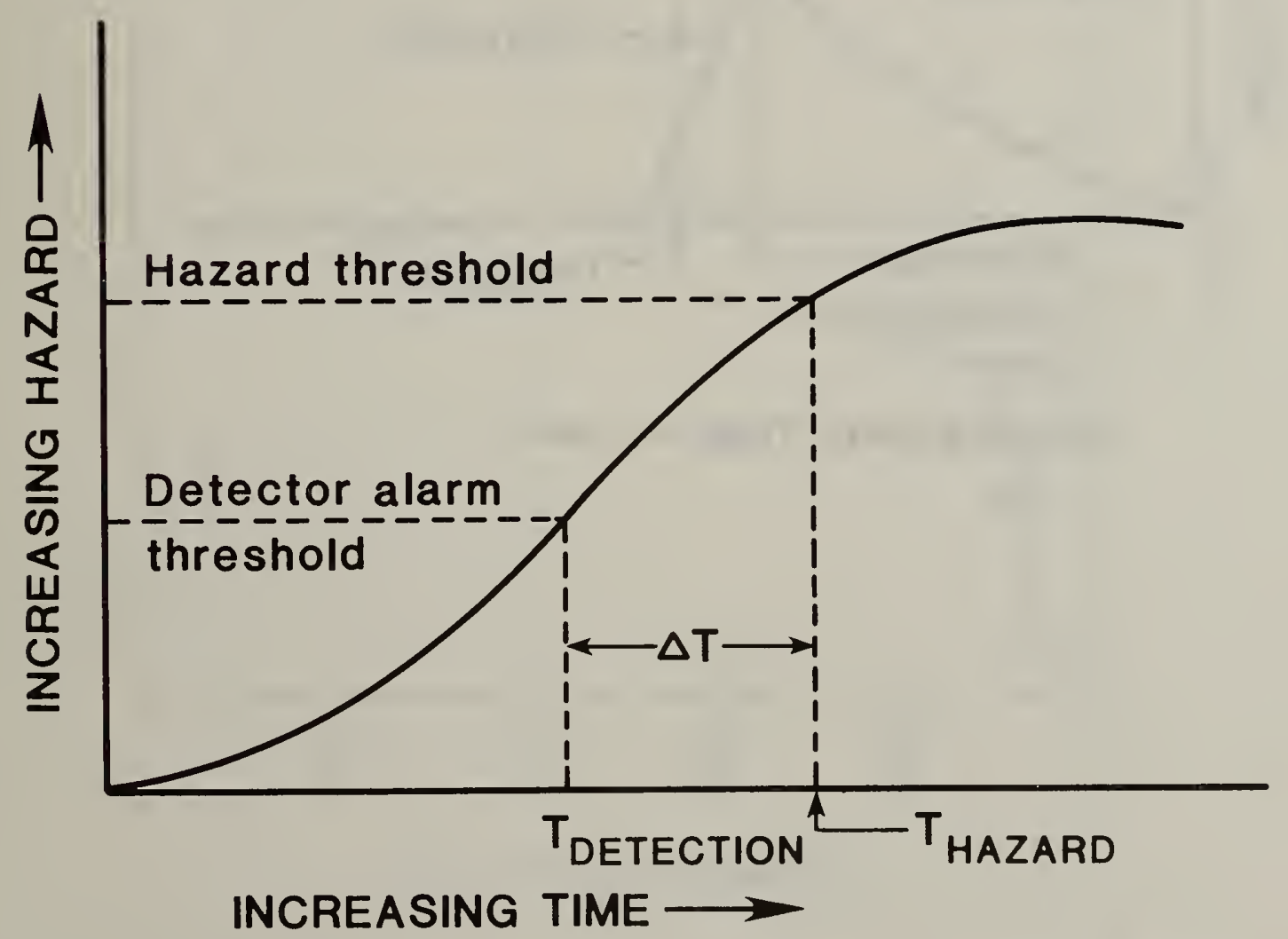

Figure 9. Graphical Illustration of Escape Time $(\Delta \mathrm{T})$ provided by Smoke Detector Alarm 


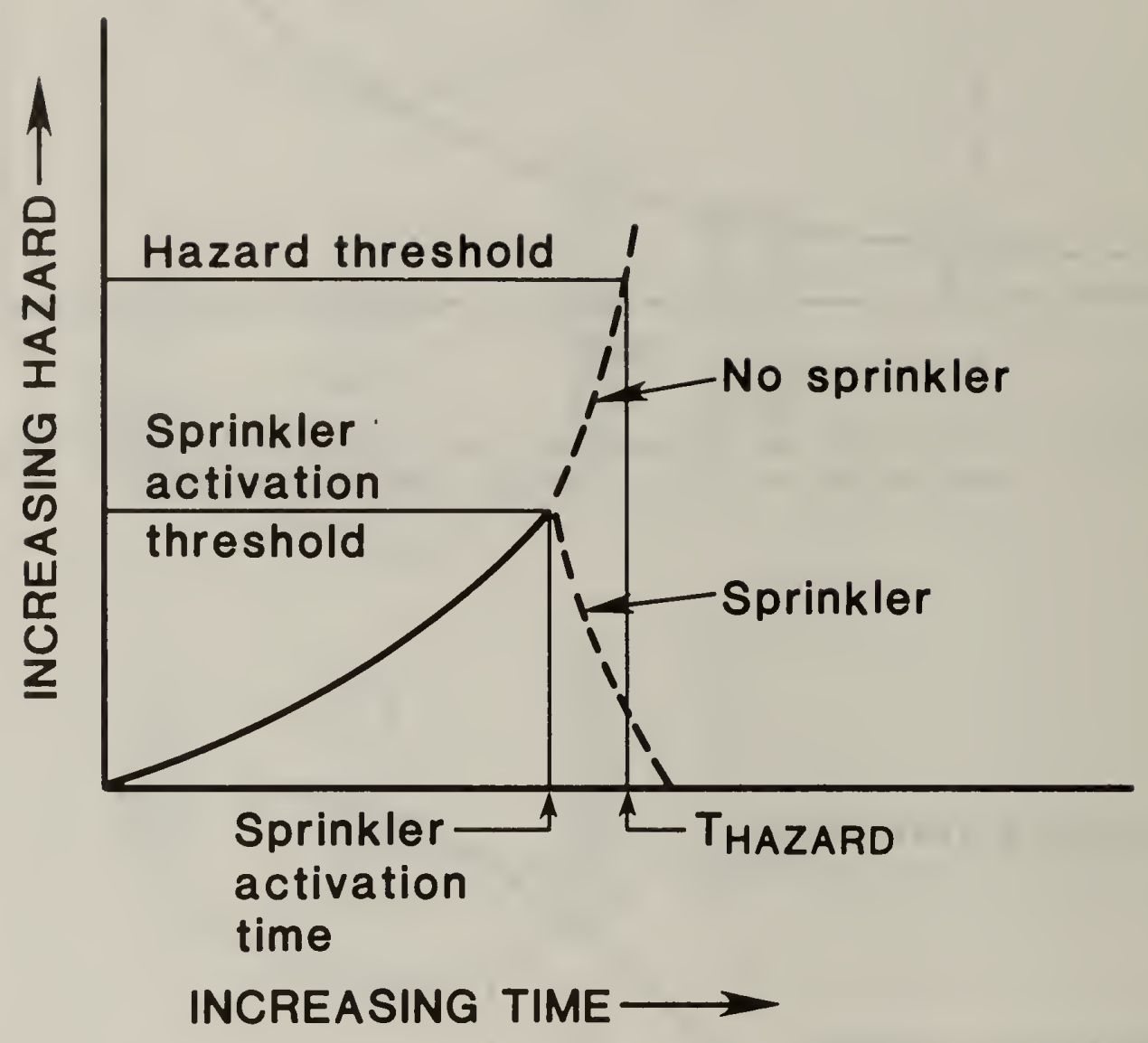

Figure 10. Graphical Illustration of Potential Impact of Sprinklers in Preventing Hazardous Conditions 


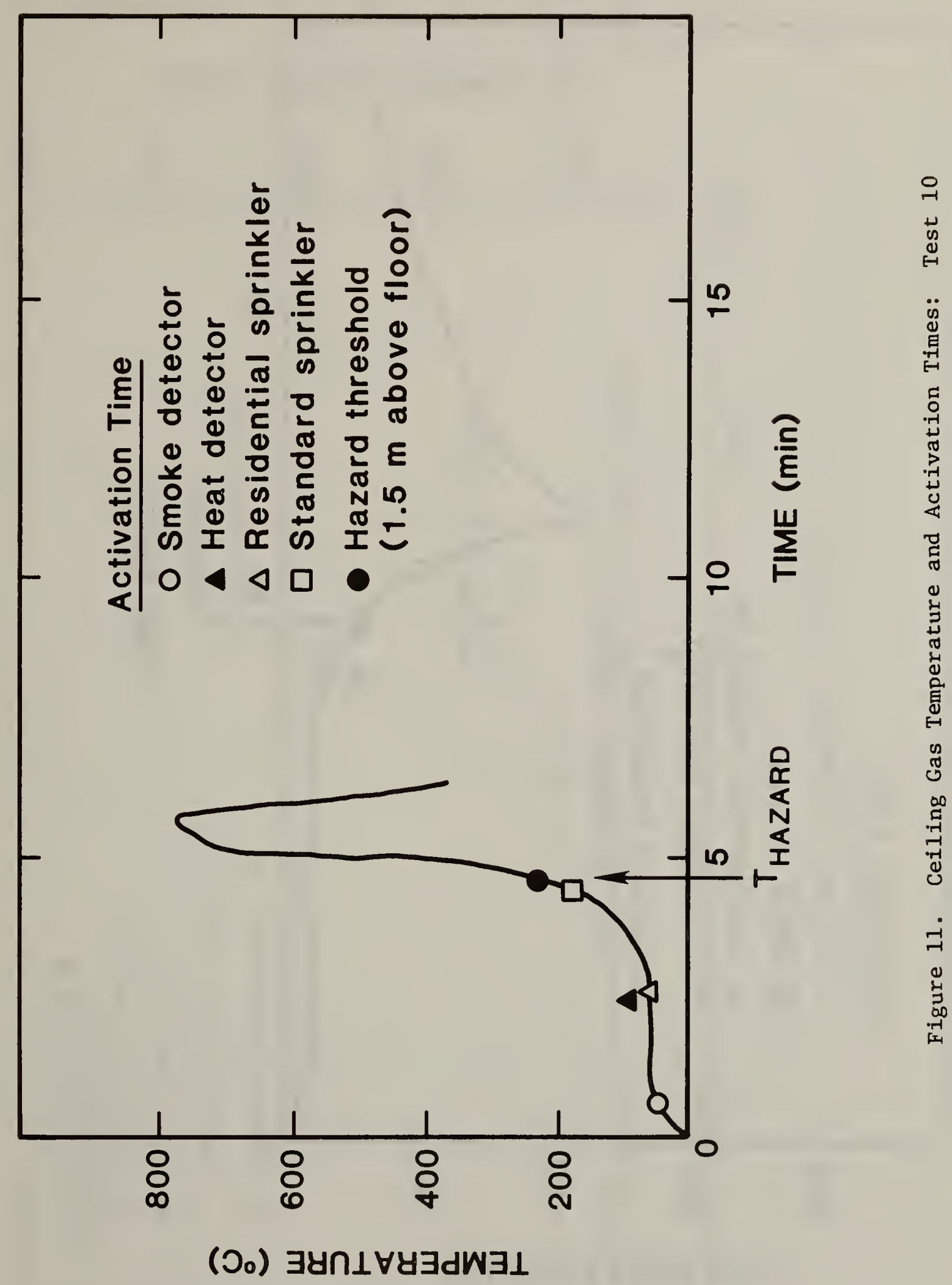




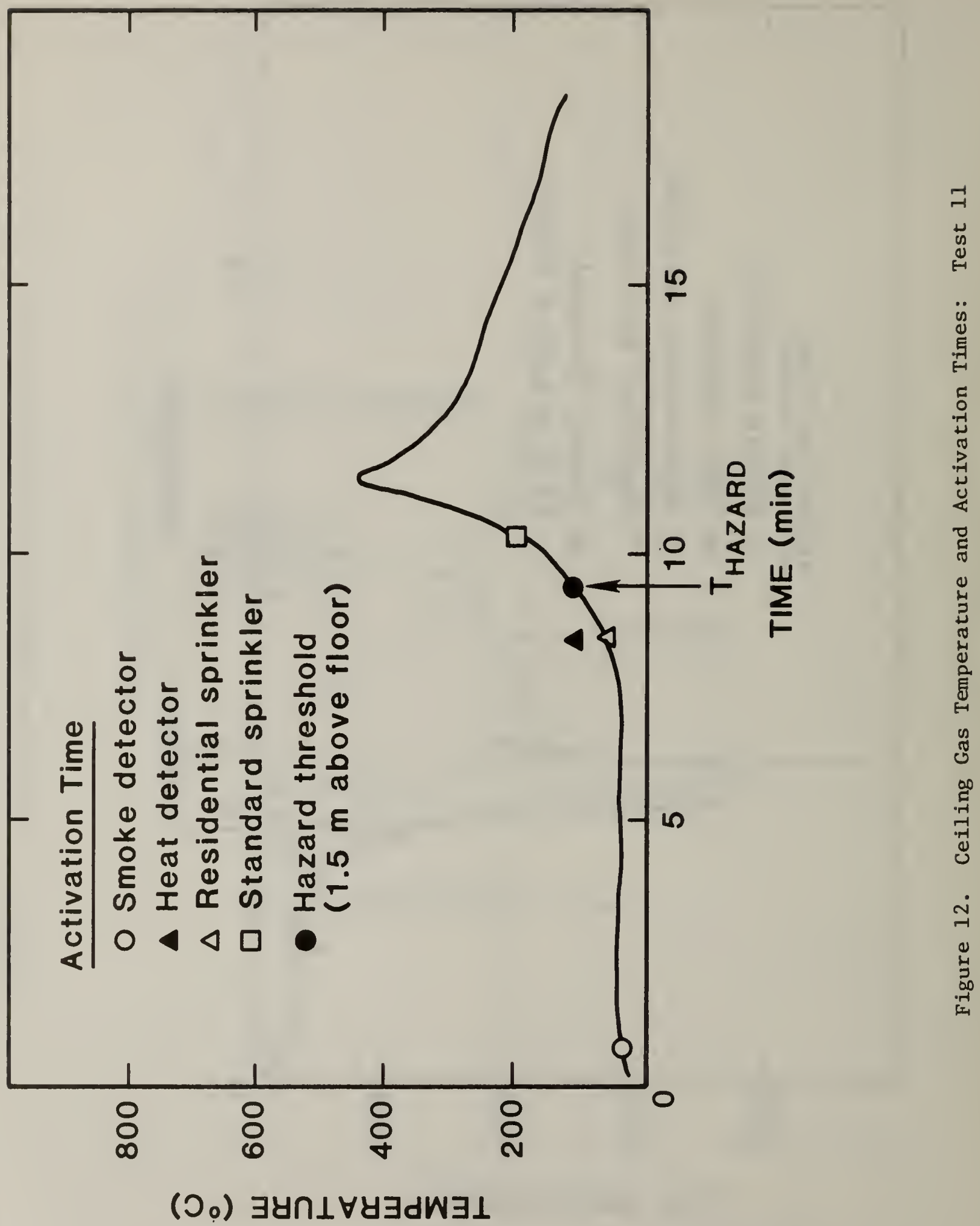




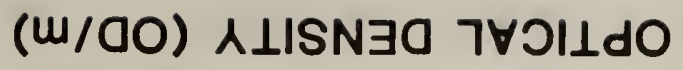

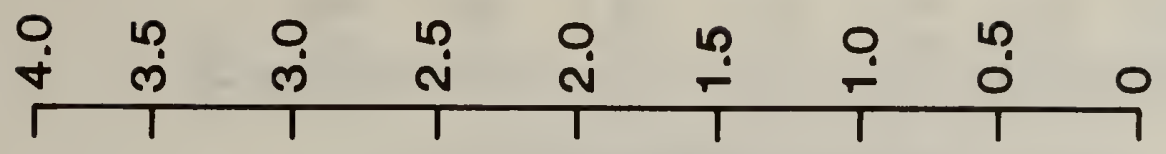

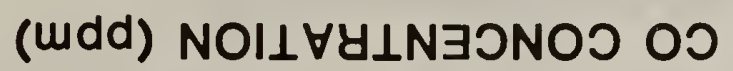

$\begin{array}{lllll}8 & 8 & 8 & 8 & 8 \\ 0 & 0 & 8 & 8 & \text { N }\end{array}$

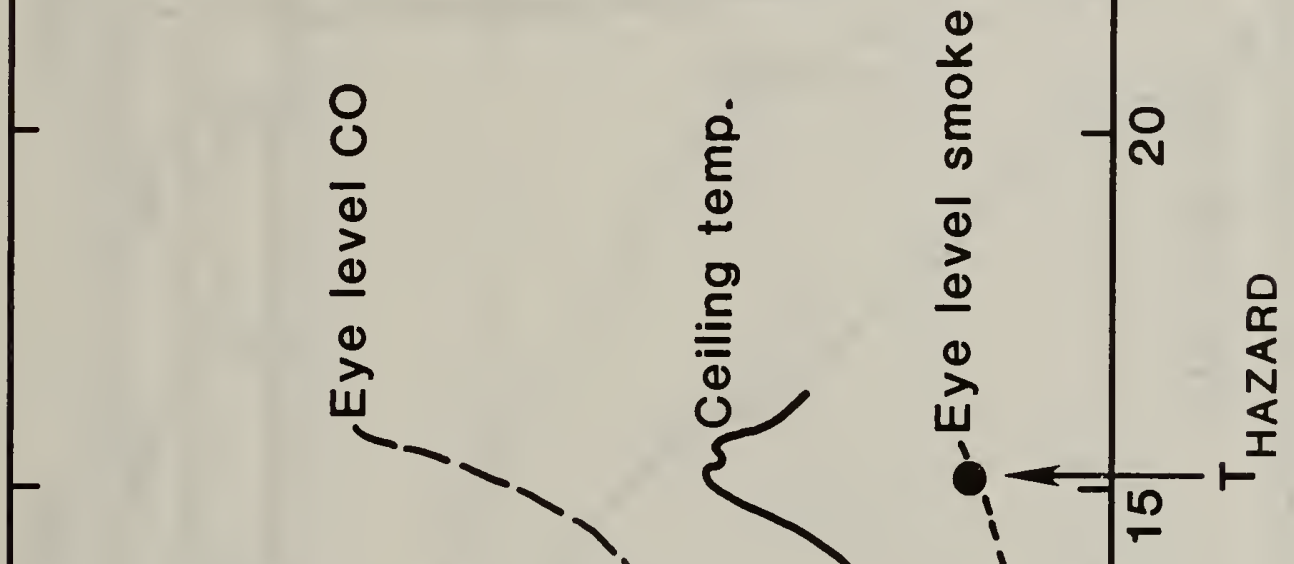




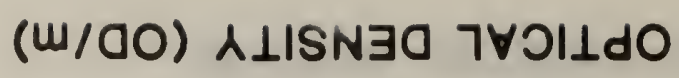

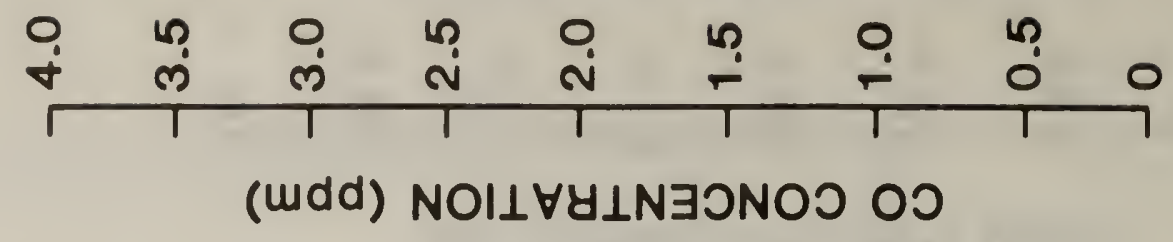

$\stackrel{\circ}{\circ}$
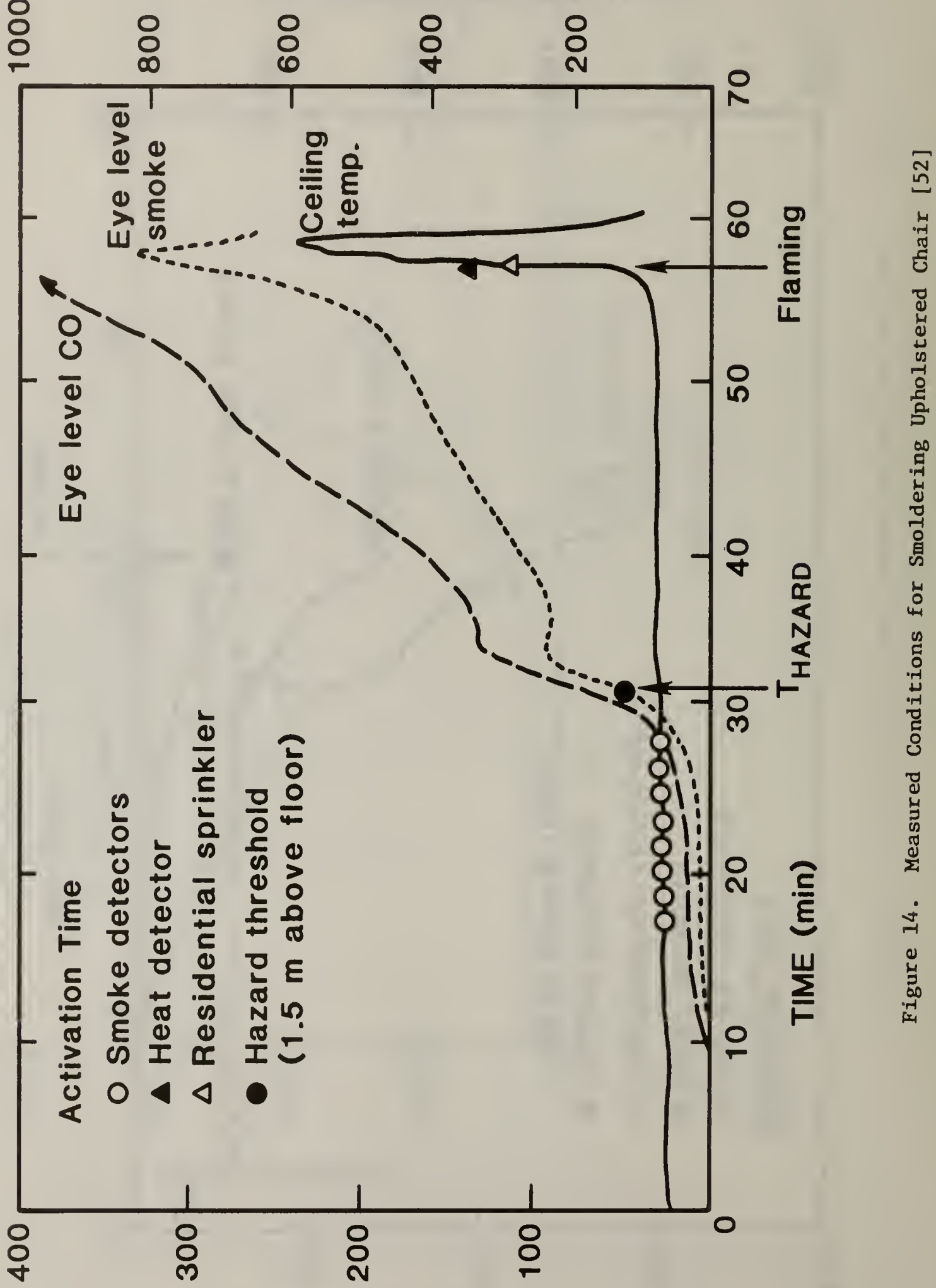

(つ०) $\exists \forall n \perp \forall y \exists d W \exists \perp$ 


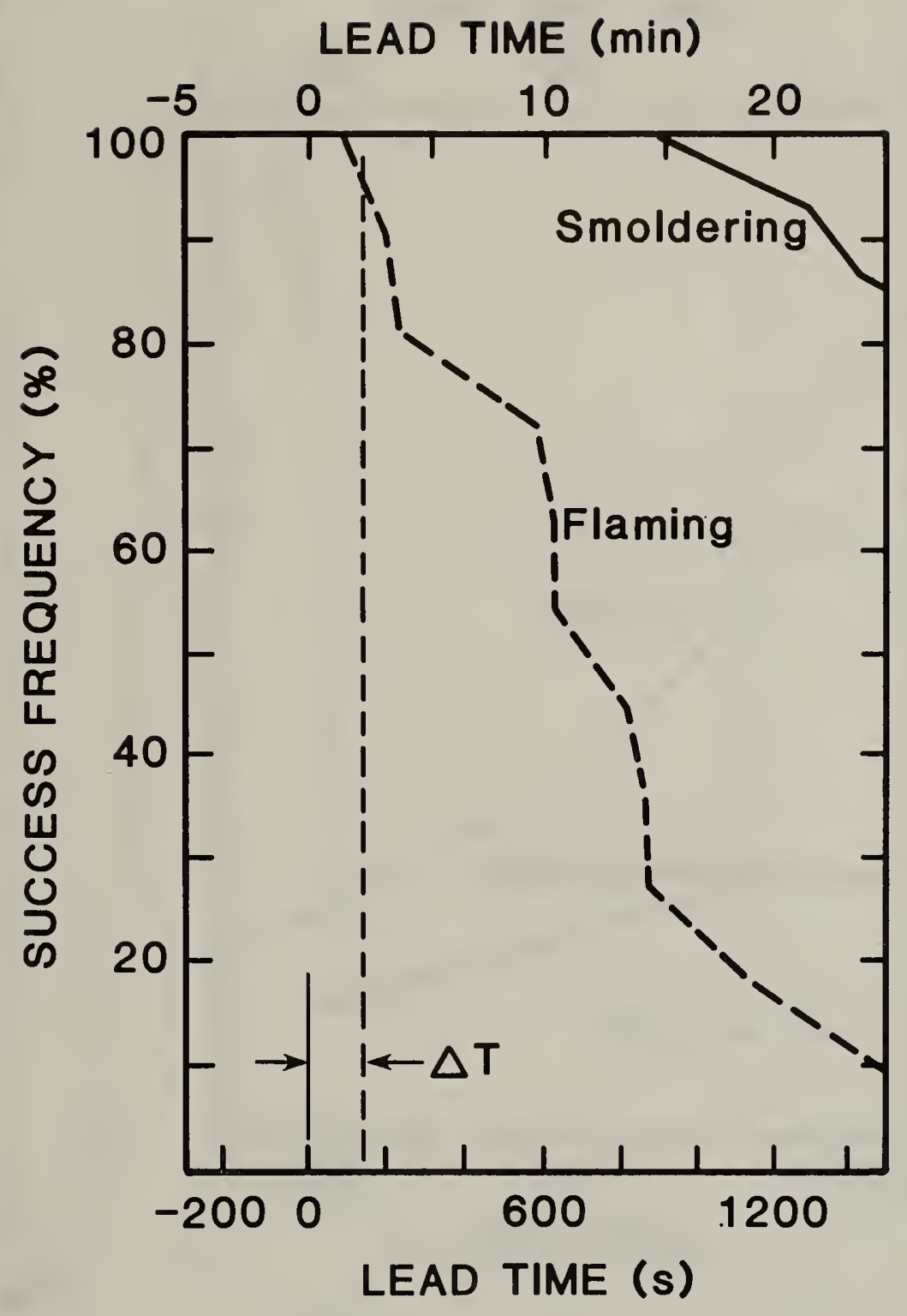

Smoke detector sensitivity - $1 \% / \mathrm{ft}$ $\Delta T=2$ minutes (minimum escape time)

Figure 15. Escape Time for Smoke Detectors Installed on Every Leve1 [53] 


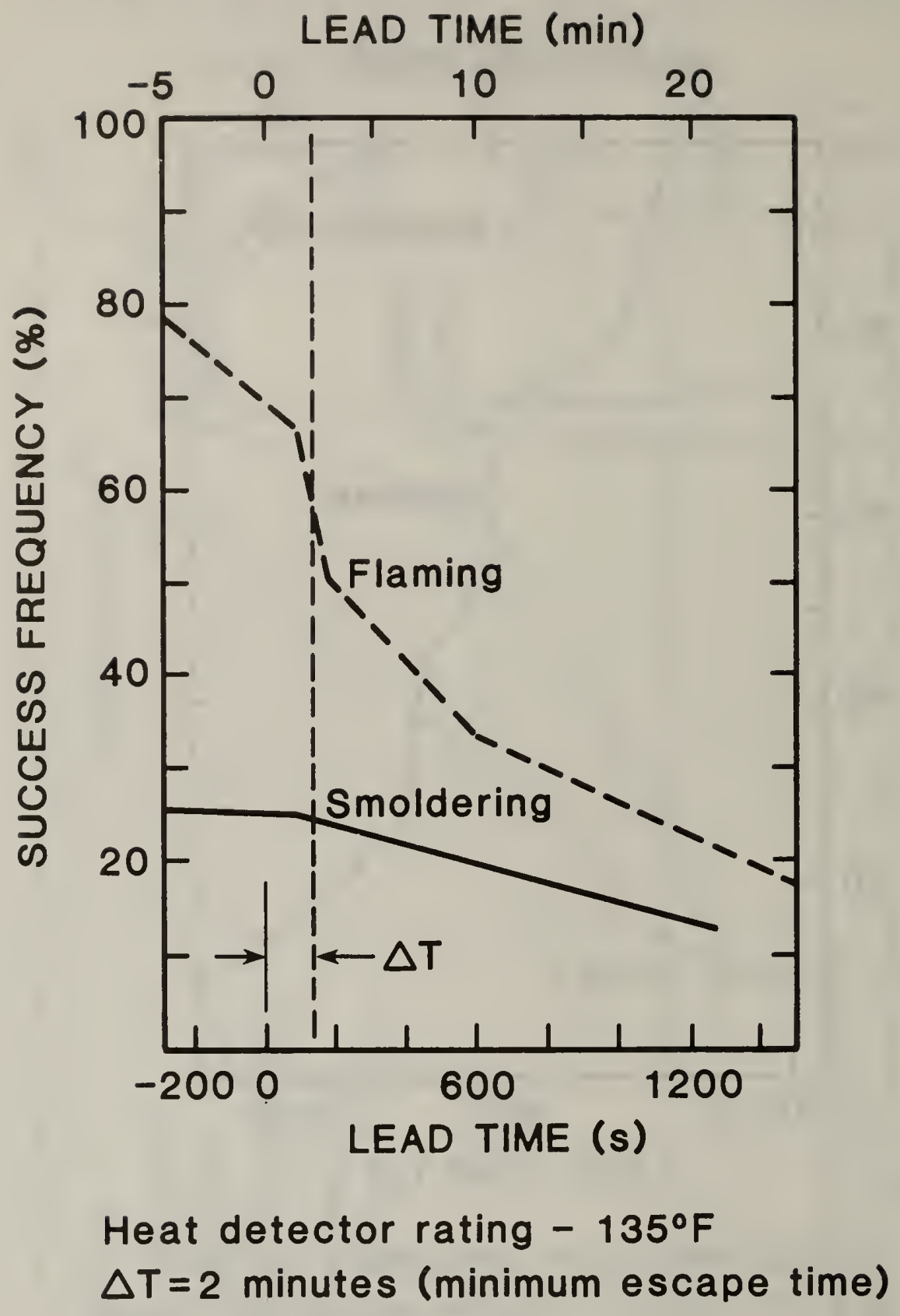

Figure 16. Escape Time for Fixed Temperature Heat Detectors Installed in Room of Origin [53] 


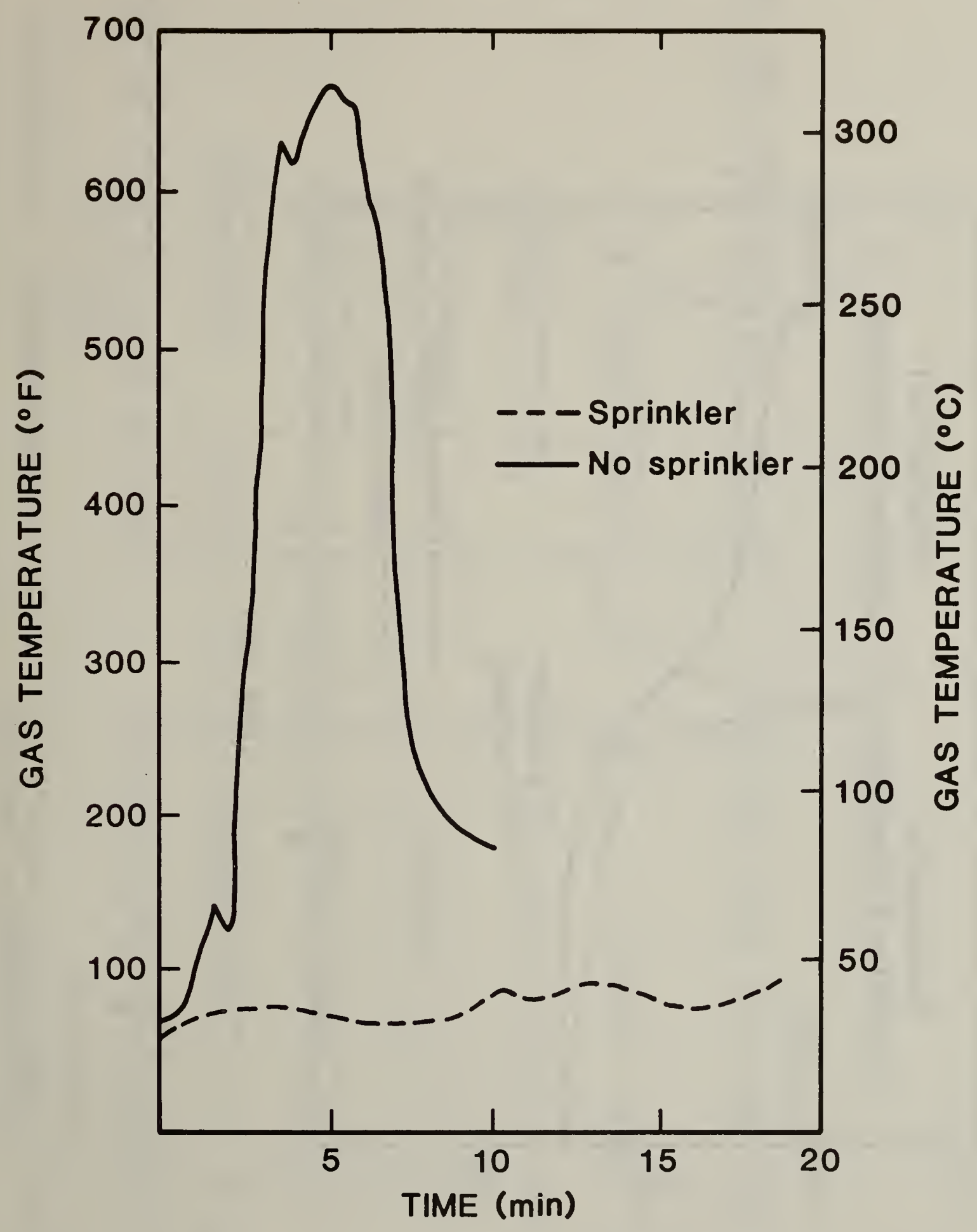

Figure 17. Ceiling Gas Temperatures in Bedroom Adjacent to Closet for Sprinklered and Unsprinklered Flaming Closet Fires [54] 


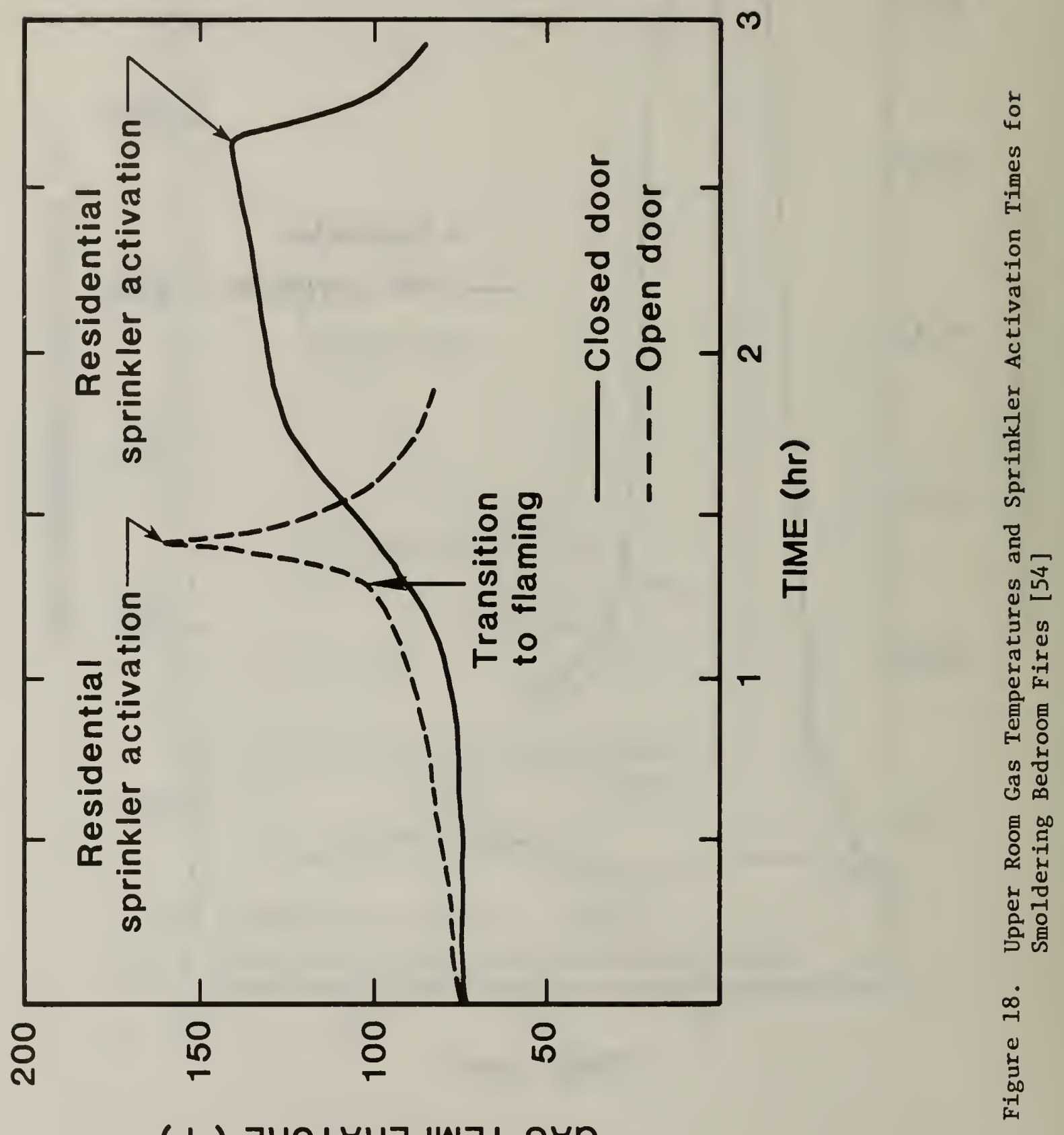

( 


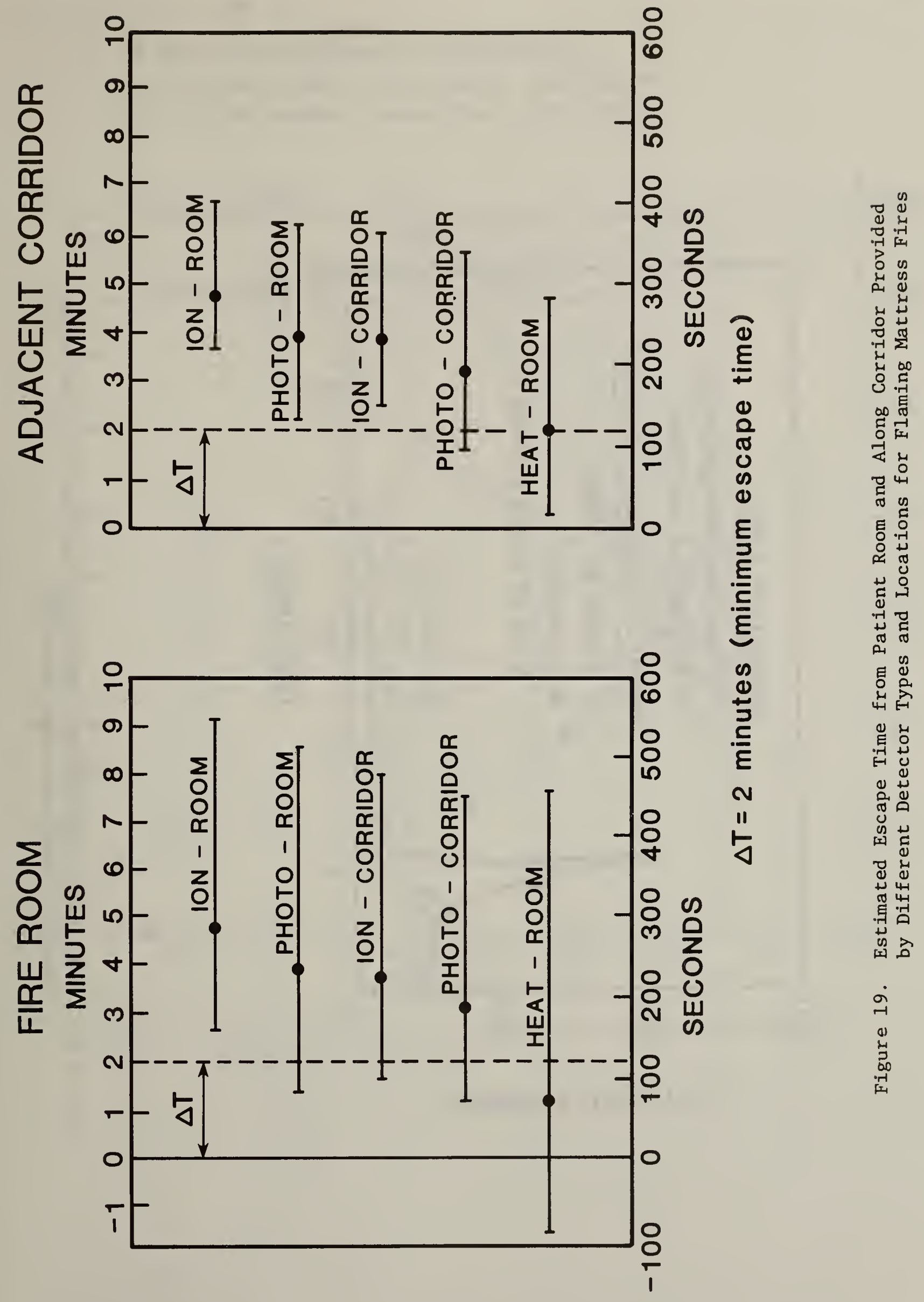




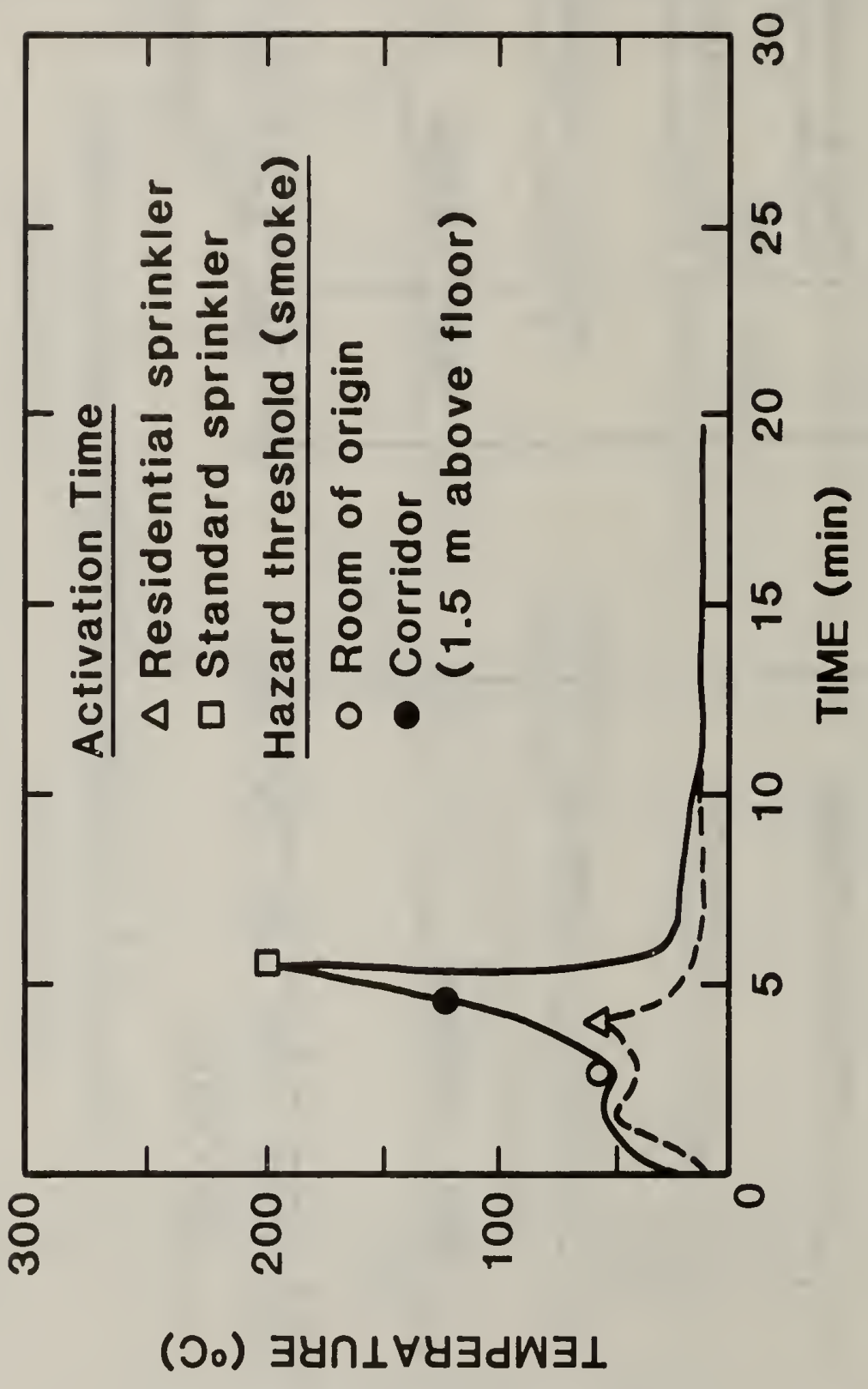

年 
- Burn room ceiling gas temperature

- Doorway smoke obscuration $0.25 \mathrm{OD} / \mathrm{m}$

- Corridor smoke obscuration $0.25 \mathrm{OD} / \mathrm{m}$

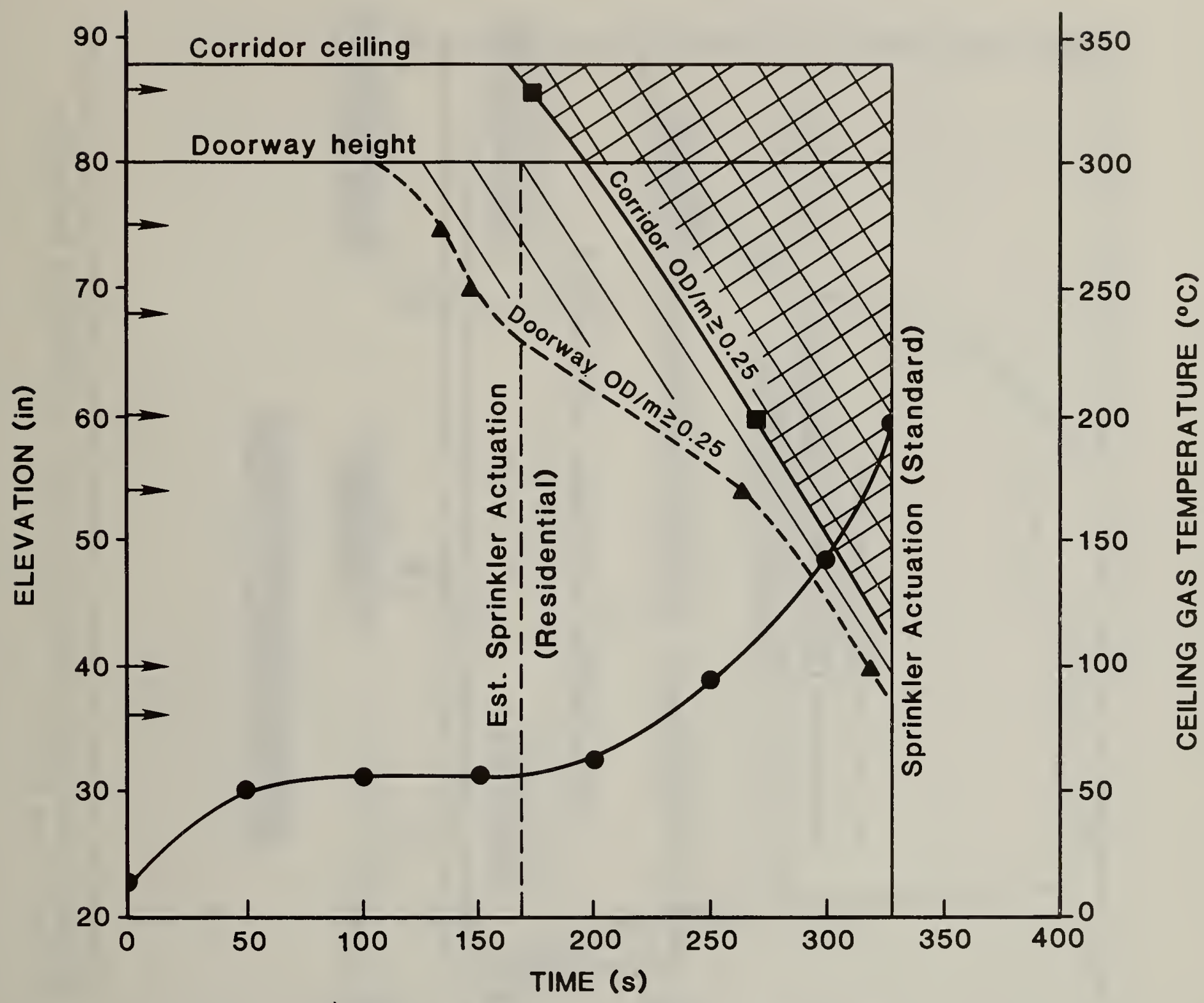

Figure 21. Effect of Different Sprinkler Activation Times on Smoke Filling in Doorway and in Corridor [57] 

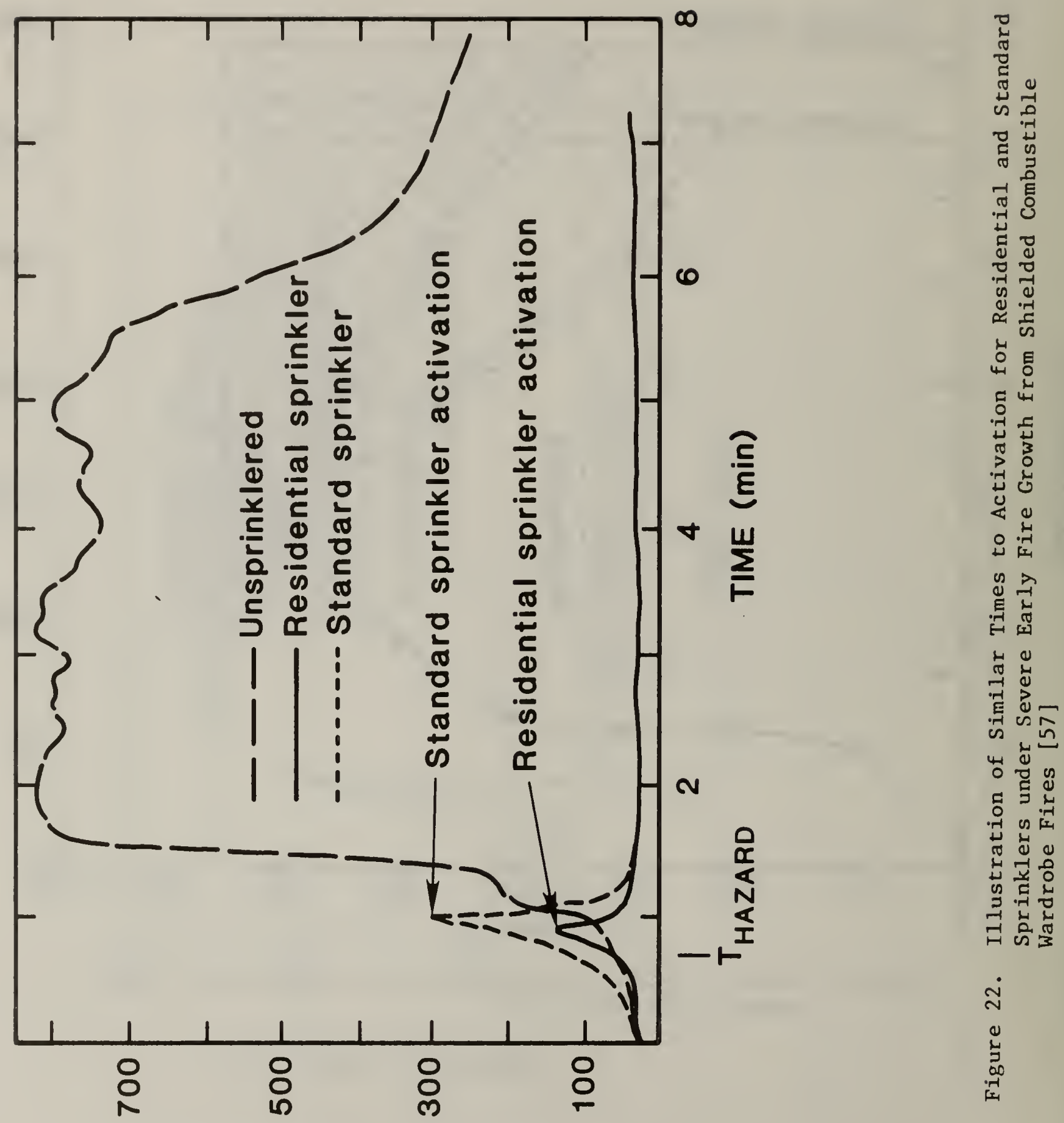

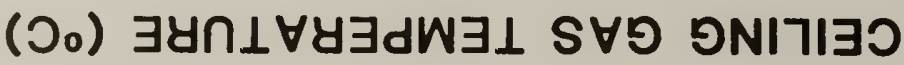




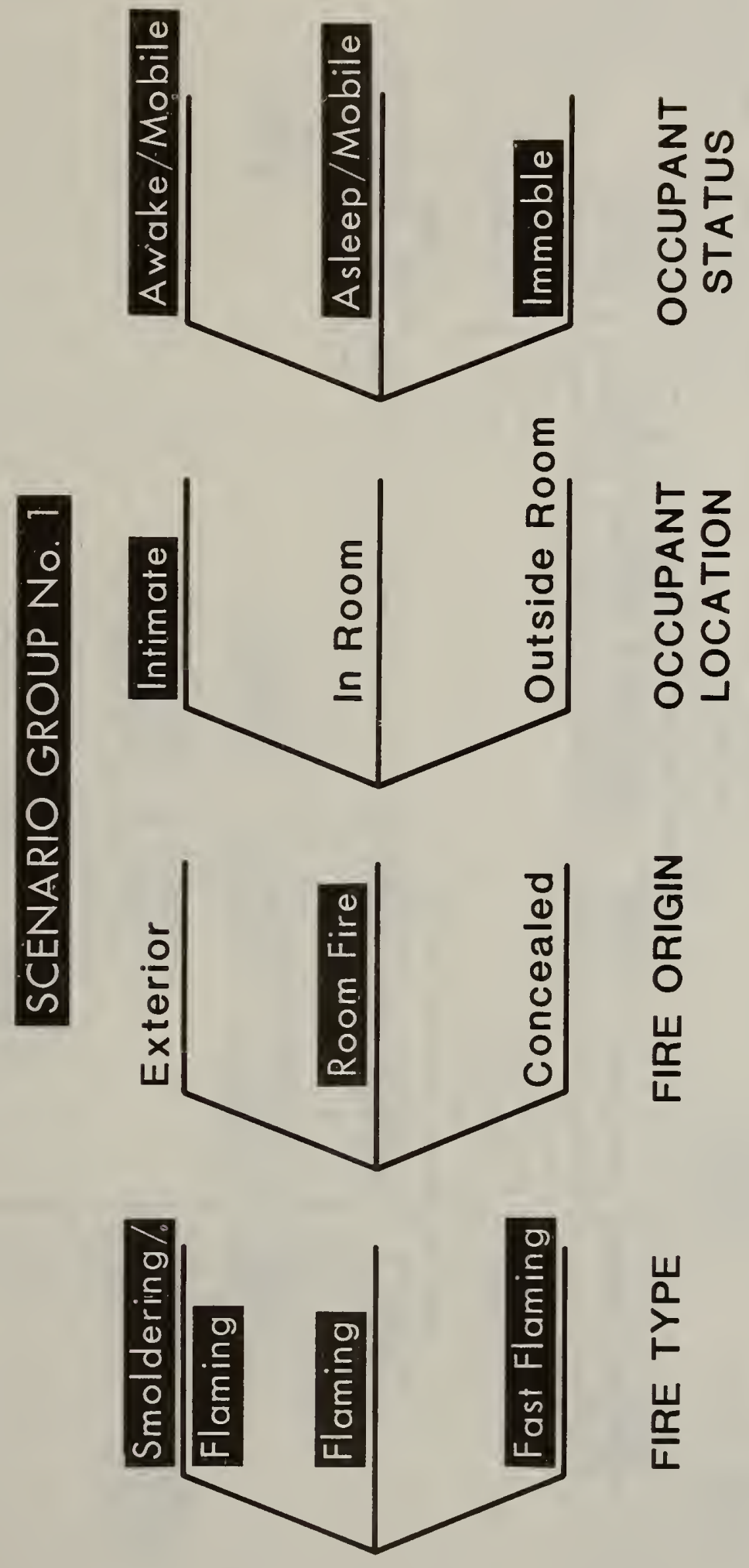

ت 


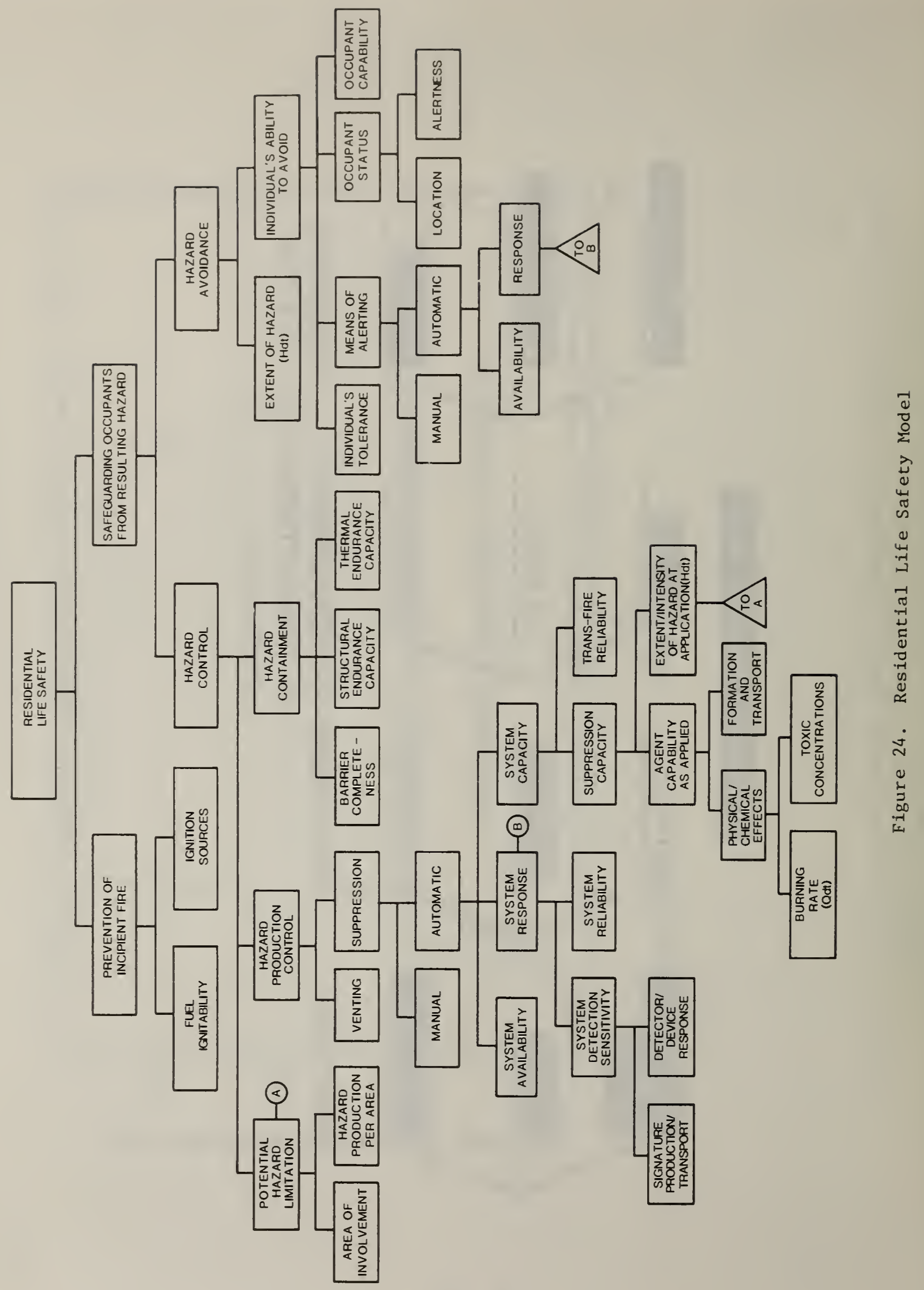




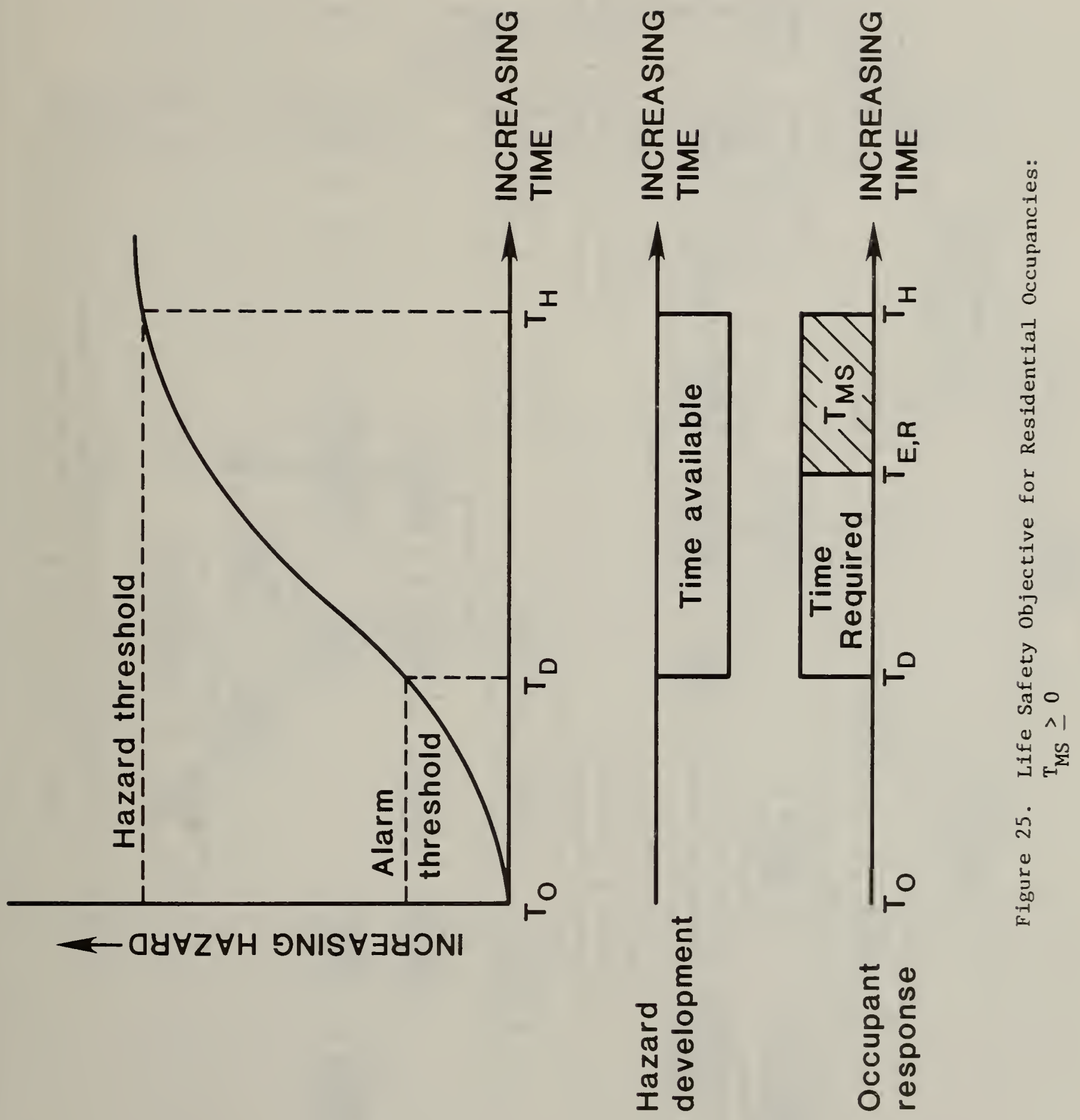




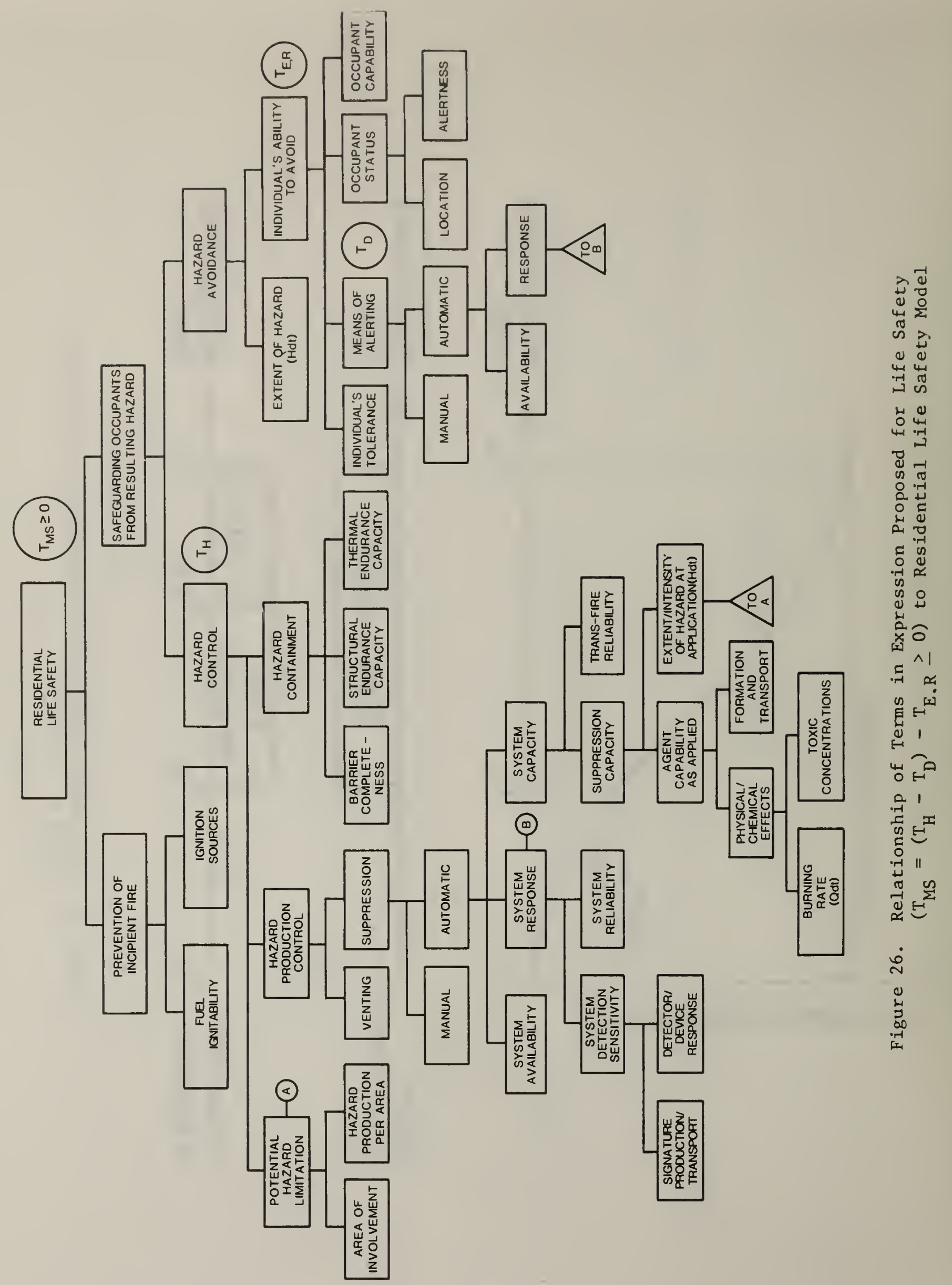


Table 1. Deaths Per Fire: One and Two Family Dwellings

\begin{tabular}{ccccc}
\hline $\begin{array}{c}\text { Deaths Per } \\
\text { Fire }\end{array}$ & $\begin{array}{r}\text { No. of } \\
\text { Fires }\end{array}$ & $\begin{array}{c}\text { Percent of } \\
\text { Total }(\%)\end{array}$ & $\begin{array}{c}\text { No. of } \\
\text { Deaths }\end{array}$ & $\begin{array}{c}\text { Percent of } \\
\text { Total }(\%)\end{array}$ \\
\hline 1 & 557 & 81 & 557 & 64 \\
2 & 86 & 13 & 172 & 20 \\
3 & 25 & 4 & 75 & 9 \\
4 & 16 & 2 & 64 & 7 \\
10 & $\frac{1}{685}$ & $\frac{-}{100}$ & $\frac{-}{868}$ & - \\
\hline
\end{tabular}

Source: 1981 NFIRS Data Base [2 ] 


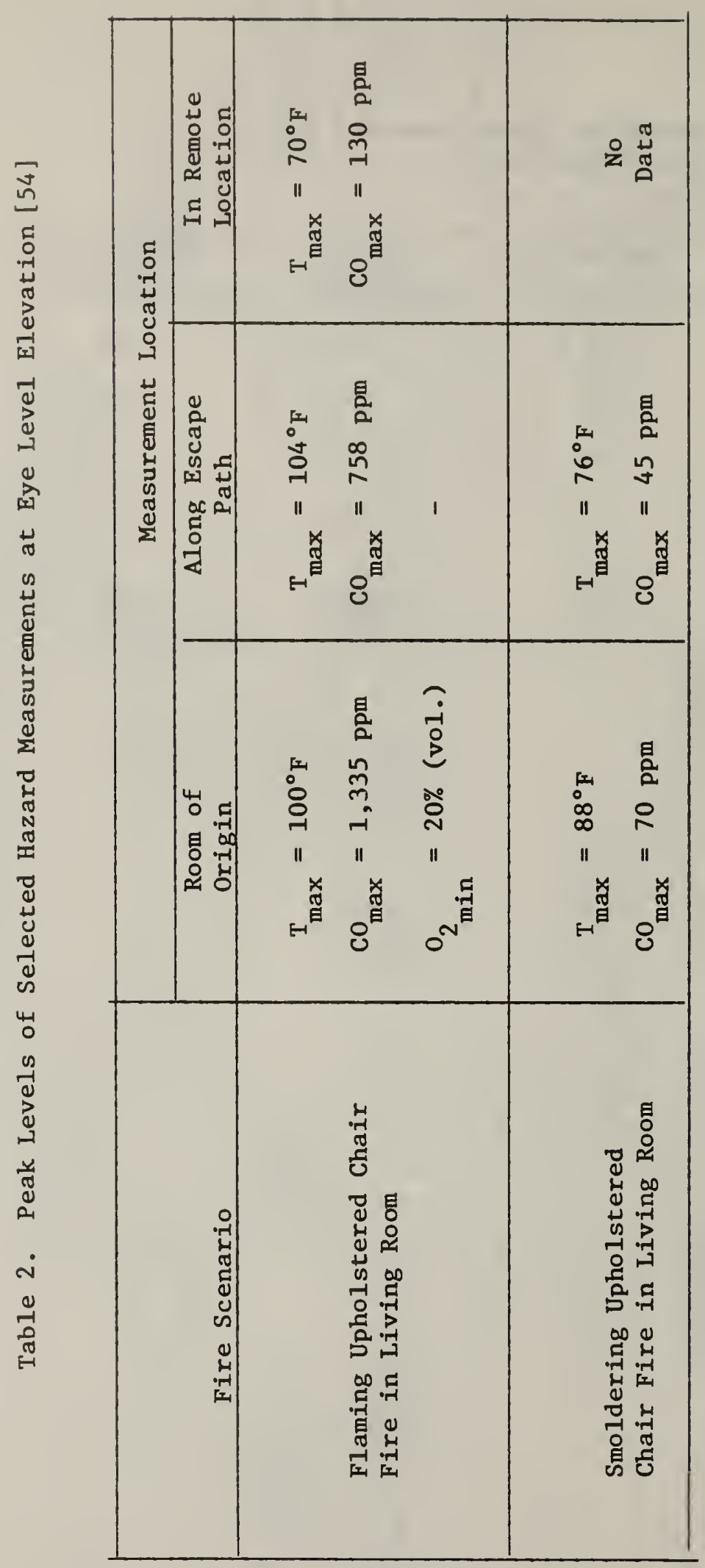




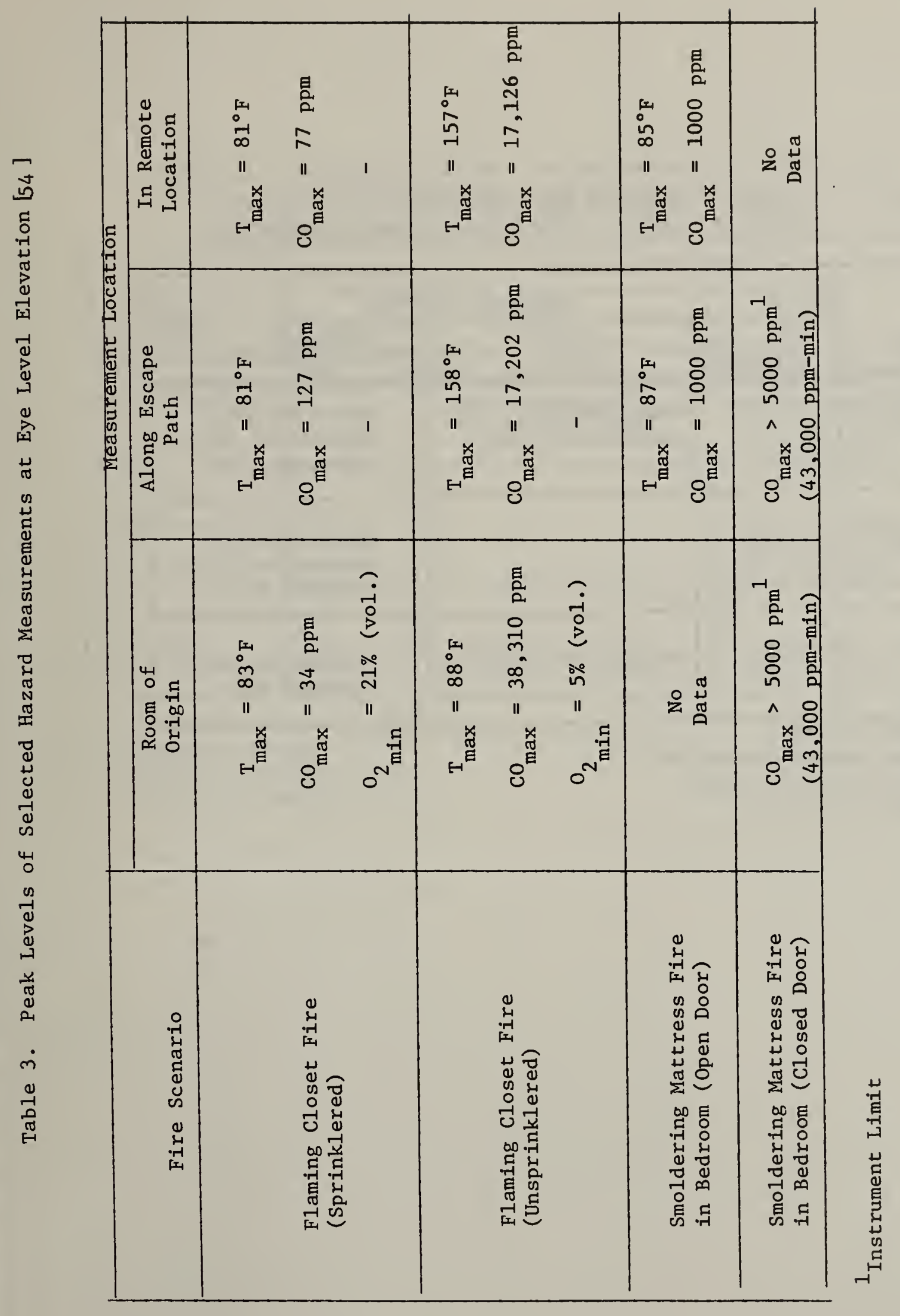


Table 4a. Occupant Conditions where Detectors or Sprinklers Provide Protection - Smoldering/Flaming Scenarios

\begin{tabular}{|c|c|c|c|}
\hline \multirow[b]{2}{*}{$\begin{array}{c}\text { Occupant } \\
\text { Status } \\
\end{array}$} & \multicolumn{3}{|c|}{ Occupant Location } \\
\hline & Intimate & $\begin{array}{c}\text { In } \\
\text { Room }\end{array}$ & $\begin{array}{c}\text { Outside } \\
\text { Room }\end{array}$ \\
\hline Asleep/Mobile & $?$ & $\begin{array}{l}\text { Smoke Detector } \\
\text { Residential Spkr (L) }\end{array}$ & $\begin{array}{l}\text { Smoke Detector } \\
\text { Residential Spkr. } \\
\text { Standard Spkr. }\end{array}$ \\
\hline Awake/Mobile & $?$ & $\mathrm{P}$ & $\begin{array}{l}\text { Smoke Detector } \\
\text { Residential Spkr. } \\
\text { Standard Spkr. }\end{array}$ \\
\hline Immobile & $?$ & Residential Spkr (L) & $\begin{array}{l}\text { Residential Spkr. } \\
\text { Standard Spkr. }\end{array}$ \\
\hline $\begin{array}{l}\text { ? Indicates } \mathrm{Ur} \\
\mathrm{L} \text { Indicates } \mathrm{L} \\
\mathrm{P} \text { Indicates } \mathrm{O} \\
\text { preempts } \mathrm{p}\end{array}$ & $\begin{array}{l}\text { wn } \\
\text { ed Prote } \\
\text { ant Acti } \\
\text { ction }\end{array}$ & Eion & \\
\hline
\end{tabular}


Table 4b. Occupant Conditions where Detectors or Sprinklers Provide Protection - Flaming Scenarios

\begin{tabular}{|c|c|c|c|}
\hline \multirow{2}{*}{$\begin{array}{c}\text { Occupant } \\
\text { Status }\end{array}$} & Intimate & $\begin{array}{c}\text { On } \\
\text { Room }\end{array}$ & $\begin{array}{c}\text { Outside } \\
\text { Room }\end{array}$ \\
\cline { 2 - 4 } Asleep/Mobile & $?$ & $\begin{array}{l}\text { Smoke Detector } \\
\text { Residential Spkr. }\end{array}$ & $\begin{array}{l}\text { Smoke Detector } \\
\text { Residential Spkr. } \\
\text { Standard Spkr. }\end{array}$ \\
\hline Awake/Mobile & $?$ & P & $\begin{array}{l}\text { Smoke Detector } \\
\text { Residential Spkr. } \\
\text { Standard Spkr. }\end{array}$ \\
\hline Immobile & $?$ & Residential Spkr. & $\begin{array}{l}\text { Residential Spkr. } \\
\text { Standard Spkr. }\end{array}$ \\
\hline
\end{tabular}

? Indicates Unknown

$P$ Indicates Occupant Action

Preempts Protection 
Table 4c. Occupant Conditions where Detectors or Sprinklers Provide Protection - Shlelded Fast Flaming Scenarios

\begin{tabular}{|c|c|c|c|}
\hline \multirow{2}{*}{$\begin{array}{c}\text { Occupant } \\
\text { Status }\end{array}$} & Int1mate & $\begin{array}{c}\text { In } \\
\text { Room }\end{array}$ & $\begin{array}{c}\text { Occupant Location } \\
\text { Room }\end{array}$ \\
\cline { 2 - 4 } & & & Smoke Detector (L) \\
\hline Asleep/Mobile & NP & NP & $\begin{array}{l}\text { Resident1al Spkr (L) } \\
\text { Standard Spkr (L) }\end{array}$ \\
\hline Awake/Mobile & NP & NP & $\begin{array}{l}\text { Smoke Detector (L) } \\
\text { Resident1al Spkr (L) } \\
\text { Standard Spkr (L) }\end{array}$ \\
\hline Imnobile & NP & NP & NP \\
\hline
\end{tabular}

NP Indicates None Provide Protection

L Indicates Limited Protection 


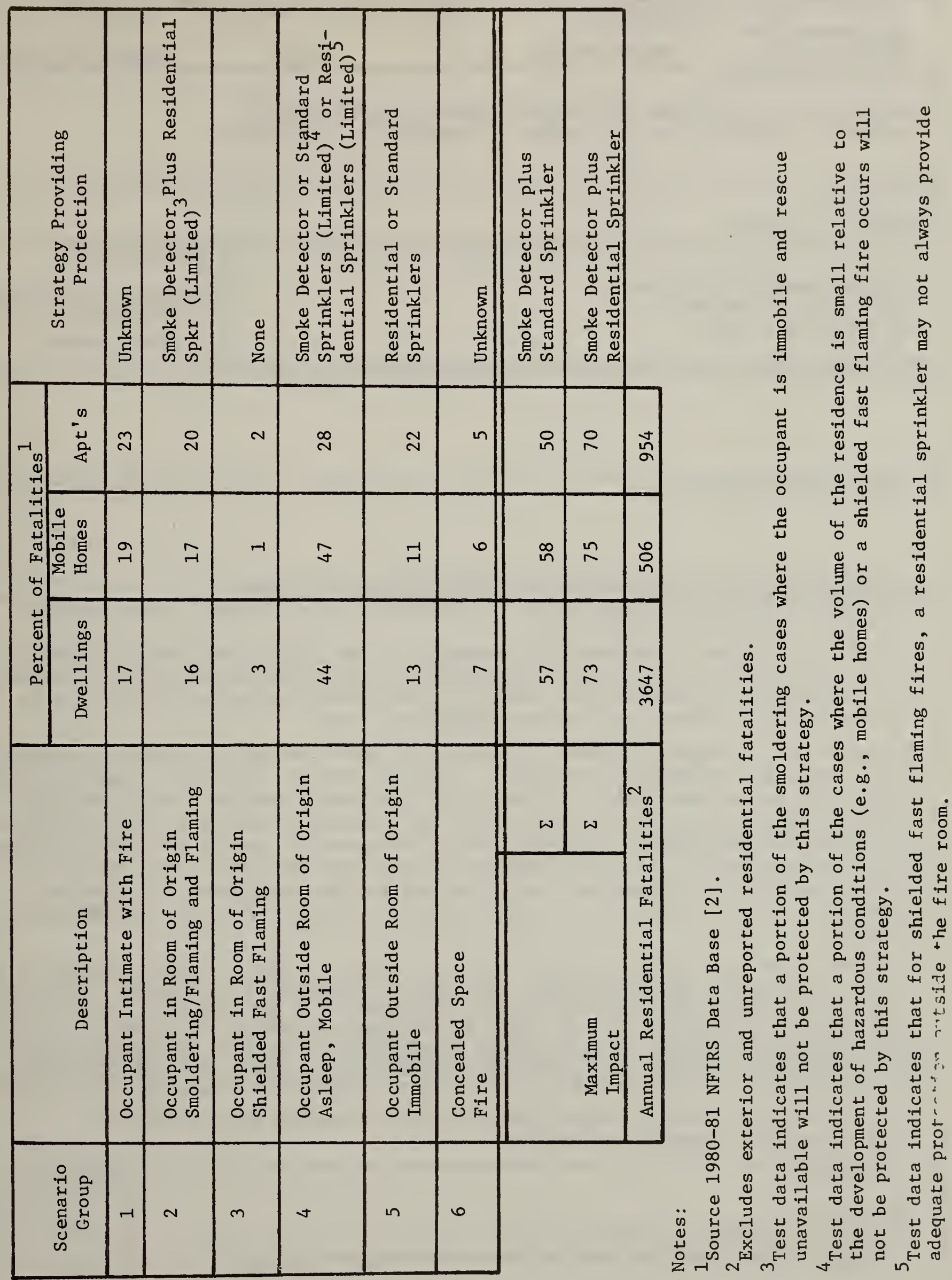




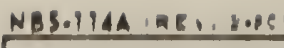

U.S. ERF T. O. COMM

BIBLIOGRAPHIC DATA

SHEET (See Instructions)

1. PUBLICATION OR

REPORT NO.

NBSIR 84-2819

2. Performing Oegan, Report Nof J, Publieasion Date

752.08

January 30,1984

4. TITLE AND SUBTITLE

ESTIMATING EFFECTIVENESS OF STATE-OF-THE-ART DETECTORS AND

ALTONAIIC SPRINKLERS ON LIFE SAFETI IN RESIDENTIAL OCCUPANCIES

5. $A U T H O R(S)$

Edward K. Budnick

6. PERFORMING ORGANIZATION (If joint or other thon NBS, see instructions)

NATIONAL BUREAU OF STANDARDS

DEPARTMENT OF COMMERCE

WASHINGTON, D.C. 20234

7. Contracugrant No.

8. Type of Report \& Perlod Covered

Final Report

9. SPONSORING ORGANIZATION NAME AND COMPLETE ADDRESS (Strot, CTt, Stot,, ZiP)

10. SUPPLEMENTARY NOTES

Document describes a computer program; SF-185, FIPS Software Summary, is attached.

11. ABSTRACT (A 200-word or less factual summary of most significant informotion. If document includes a signlficont tibliography or literature survey, mention it here)

The report provides a qualitative assessment of the life safety impact of early warning fire detection and automatic sprinkler technology in residential occupancies. This assessment is based on the results of full scale studies and statistics on residential fire fatalities from the NFIRS data base.

Estimates of the impact of three alternatives, smoke detectors, standard automatic sprinklers, and residential sprinklers, are provided for major fire hazard scenarlos in residential occupancies. The results of this study indicate that significant life safety benefits can be derived from broad application of detectors and sprinklers in all residential buildings. Further work is necessary to reduce the gaps which exist in our understanding of the performance limits, cost-effectiveness, and reliability.

of these devices. In addition, there are residential scenarios, for example, occupants intimately exposed to a fire, where the impact of these devices appears marginal.

A quantitative approach is outlined that can lead to a more accurate assessment of the impact of detectors and sprinklers. An initial framework is presented which identifies the key parameters for residential life safety. A mathematical expression is proposed as a success criterion. Work is underway to extend the framework to sufficient detail to permit formulation of appropriate analytical expressions necessary for quantitative evaluation of specific parameters and their interrelationships.

12. KEY WORDS (Six to twelve entries; olphobetical order; copitallze only proper names; ond seporate key words by semicolons)

Fire losses; life safety; residential bulldings; residential sprinklers, smoke detectors; standard sprinklers.

13. AVAILABILITY

XUUnlimited

For Official Distribution. Do Not Release to NTIS

Order From Superintendent of Documents, U.S. Government Printing Office, Washington, D.C. 20402.

14. NO. OF

PRINTED PAGES

81

X Order From Natıonal Technical Information Service (NTIS), Springfield, VA. 2216I 

